\title{
Multiphasic value biases in fast-paced decisions
}

\author{
Elaine A. Corbett ${ }^{\star 1,2}$, L. Alexandra Martinez-Rodriguez ${ }^{2}$, Cian Judd ${ }^{1}$, Redmond G. O'Connell ${ }^{1}$ and \\ Simon P. Kelly ${ }^{1,2}$
}

${ }^{1}$ Trinity College Institute of Neuroscience and School of Psychology, Trinity College Dublin, Dublin 2, Ireland

${ }^{2}$ School of Electrical and Electronic Engineering and UCD Centre for Biomedical Engineering, University College Dublin, Belfield, Dublin 4, Ireland

* Corresponding author: Elaine A Corbett (corbetel@tcd.ie)

Abstract Perceptual decisions are biased toward higher-value options when overall gains can be improved. When stimuli demand immediate reactions, the neurophysiological decision process dynamically evolves through distinct phases of growing anticipation, detection and discrimination, but how value biases are exerted through these phases remains unknown. Here, by parsing motor preparation dynamics in human electrophysiology, we uncovered a multiphasic pattern of countervailing biases operating in speeded decisions. Anticipatory preparation of higher-value actions began earlier, conferring a "starting point"- advantage at stimulus onset, but the delayed preparation of lower-value actions was steeper, conferring a value-opposed buildup rate bias. This, in turn, was countered by a transient deflection toward the higher value action evoked by stimulus detection. A neurally-constrained process model featuring anticipatory urgency, biased detection, and accumulation of growing stimulus-discriminating evidence, successfully captured both behavior and motor preparation dynamics. Thus, an intricate interplay of distinct biasing mechanisms serves to prioritise time-constrained perceptual decisions.

\section{Introduction}

Perceptual decision making is generally well explained by a process whereby evidence is accumulated over time up to a bound that can trigger an action (Brown and Heathcote, 2008; Link and Heath, 1975; Ratcliff, 1978; Smith and Ratcliff, 2004; Usher and McClelland, 2001). In most models based on this principle, a given response time (RT) is made up of two temporal components, where the decision variable is either building at a stationary rate ("drift rate") determined by a stable evidence representation, or is suspended, during "non-decision" delays associated with sensory encoding and motor execution. This simple scheme, developed primarily through the study of slow, deliberative perceptual decisions, affords two ways to explain how faster and more accurate responses are made to higher-value or more probable stimuli: through modulating the starting point or drift rate of the process (Feng et al., 2009; Leite and Ratcliff, 2011; Mulder et al., 2012; Ratcliff and McKoon, 2008; Simen et al., 2009; Summerfield and Koechlin, 2010; Urai et al., 2019; Voss et al., 2004; White and Poldrack, 2014). Corresponding adjustments have been reported in neurophysiological recordings from motor-related areas of the brain (de Lange et al., 2013; Hanks et al., 2011; Rorie et al., 2010). However, recent work has highlighted additional dynamic elements of the decision process whose contributions to choice performance are likely to be accentuated when stimuli require immediate action.

First, when stimulus onset is predictable, anticipatory activity in motor preparation regions can begin to forge a decision even before the stimulus appears. While standard models do allow for anticipatory processing in the setting of the starting point from which the accumulator evolves after sensory encoding, neurophysiological data have revealed that anticipatory motor preparation is dynamic, proceeding on a trajectory aimed at eventually crossing an action-triggering threshold by itself even in the absence of sensory input (Feuerriegel et al., 2019; Kelly et al., 2020; Stanford et al., 2010). Such evidence-independent buildup components, often labelled as 'urgency signals,' effectively implement a collapsing bound on cumulative evidence, so that decisions that continue 
bioRxiv preprint doi: https://doi.org/10.1101/2021.03.08.434248; this version posted March 9,2021 . The copyright holder for this preprint (which was not certified by peer review) is the author/funder, who has granted bioRxiv a license to display the preprint in perpetuity. It is made available under aCC-BY 4.0 International license.

longer can be completed based on less evidence (Churchland et al., 2008; Hanks et al., 2014; Murphy et al., 2016; Shinn et al., 2020; Steinemann et al., 2018; Thura and Cisek, 2014).

Second, for many suddenly-onsetting stimuli, sensory evidence of their distinguishing features emerges some time after the initial sensory neural response signalling their onset (Afacan-Seref et al., 2018; Smith and Ratcliff, 2009), meaning that detection precedes discrimination. In the case of the widely-studied random dot motion stimulus, recent work shows that behavior is well captured by a model in which accumulation begins at the onset of sensory encoding but where it takes a further $400 \mathrm{~ms}$ for the direction information to stabilise (Smith and Lilburn, 2020). In fact, serial detection and discrimination phases are reflected in human electrophysiological signatures of differential motor preparation during fast, value-biased decisions about other sensory features. Specifically, these signals show biased stimulus-evoked changes initially in the direction of higher value before being re-routed towards the correct sensory alternative (Afacan-Seref et al., 2018; Noorbaloochi et al., 2015), in line with previously proposed dual-phase models (Diederich and Busemeyer, 2006).

Thus, in time-pressured situations decision formation is not suspended until sensory representations stabilise, but rather proceeds through a concerted sequence of anticipatory, detection and discriminatory processing phases. Although previous work has established the potential importance of these individual phases (Afacan-Seref et al., 2018; Diederich and Busemeyer, 2006; Kelly et al., 2020; Noorbaloochi et al., 2015; Smith and Lilburn, 2020; Stanford et al., 2010), there exists no detailed computational account of how value-biased decision formation dynamics unfold through all three of them. In this study we used two complementary human electrophysiological signatures of motor preparation during performance of a sudden-onset random dot motion discrimination task under a tight deadline, to forge such an account.

We observed a complex pattern of distinct biases exerted across multiple phases including an initial anticipatory buildup in motor preparation for the high-value alternative, a later but steeper anticipatory buildup for the low-value alternative and then, immediately following stimulus onset, a further transient burst toward the high-value alternative. By incorporating urgency signal model components whose initial amplitude and buildup rate were constrained to match the corresponding measures of anticipatory motor preparation we were able to adjudicate among several alternative multi-phase decision process models. We found that a model that featured 1) an initial, transient detection-triggered deflection toward the higher value alternative and 2) gradually-increasing discriminatory sensory evidence, best accounted for behavior, as well as recapitulating the fast dynamics of stimulus-evoked, differential motor preparation. Together, the findings show that, rather than simply enhancing all parameters of the decision process in favour of high-value alternatives, the neural decision architecture has the flexibility to apply biases in opposing directions to different process components, in a way that affords low-value decision signals the chance to "catch-up" when smaller rewards can be attained.

\section{Results}

Behavior. Participants performed fast-paced motion direction discrimination using the well-studied random dot kinematogram (RDK) stimulus (Roitman and Shadlen, 2002) with a preceding cue indicating the more valuable direction. We recorded scalp electroencephalography (EEG) from seventeen participants performing the task in three blocked regimes: high coherence with a very short deadline; low coherence with a slightly longer deadline; and the two coherences interleaved with the longer deadline (Figure 1A). While we were primarily focused on the value biasing dynamics in common across these challenging regimes, these manipulations allowed us to further explore potential regime differences in the degree of the uncovered effects. In each trial, colored arrows appeared prior to the stimulus onset indicating the respective value of a correct response in the two possible directions (left and right), and participants responded by clicking a mouse button with their corresponding thumb. Correct responses between $100 \mathrm{~ms}$ after stimulus onset and the deadline resulted in the points associated with the color cue; otherwise, no points were earned. 
The value manipulation produced strong behavioral effects. Accuracy was higher for high-value trials than low-value trials $\left(F(1,16)=60.6, p<0.001\right.$, partial $\left.\eta^{2}=0.79\right)$, and the median RTs for correct responses were shorter $\left(F(1,16)=80.9, p<0.001\right.$, partial $\left.\eta^{2}=0.84\right)$. These effects were manifest to a strong degree across all 4 conditions, though overall accuracy and RT varied (Figure 1B).

A

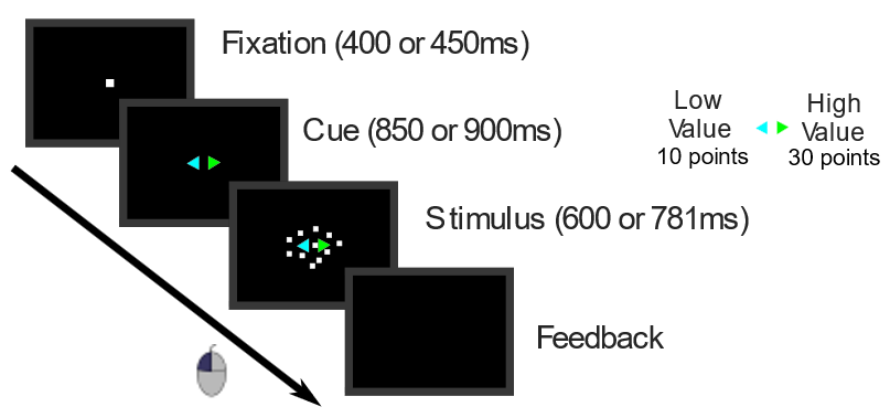

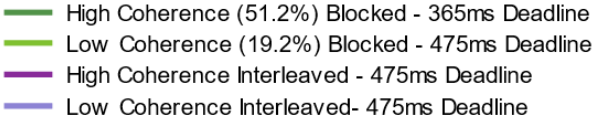

B

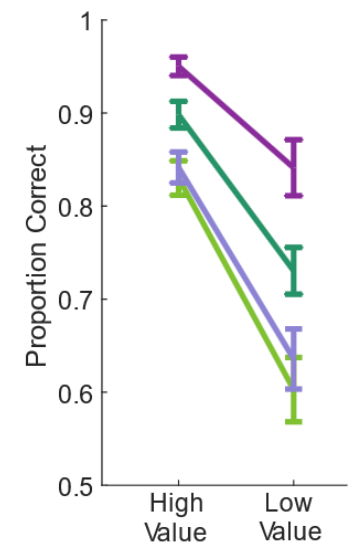

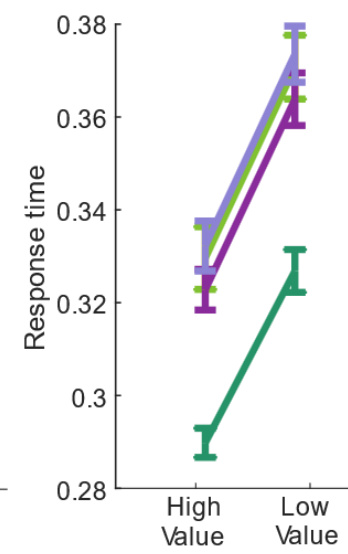

Figure 1: Value-cued motion direction discrimination task and behavioral data. A Trial structure with task conditions below. B Mean and standard error across participants for proportion correct and median RTs of correct responses. In addition to the large value effects, task condition affected accuracy $\left(F(3,48)=60.3, p<0.001\right.$, partial $\left.\eta^{2}=0.79\right)$ and correct $R T s(F(3,48)=38.1, p<0.001$, partial $\left.\eta^{2}=0.71\right)$; the high coherence conditions were more accurate $(p<.001$ for blocked and interleaved) and the blocked high-coherence condition, with the shorter deadline, was the fastest $(p<.001$ compared to other 3 conditions). Pairwise comparisons revealed no significant difference between the two low-coherence conditions $(p=0.1,0.6$; $B F 10=0.87,0.28$ for accuracy and correct RTs respectively). The Condition $x$ Value interaction was significant for accuracy $(F(3,48)=6.4, p=0.005$, partial $\left.\eta^{2}=0.29\right)$ but not correct RTs $(p=0.7)$.

EEG Signatures of Motor Preparation. To trace motor preparation for the left and right hand responses, from the period of stimulus anticipation through to response completion, we measured decreases in spectral EEG amplitude in the Beta band (integrated over 14-30Hz) at selected motor electrodes in the right and left hemispheres (Donner et al., 2009; O'Connell et al., 2012). Prior to stimulus onset, motor preparation began to build in response to the value cue, first for the highvalue alternative and later for the low-value alternative $\left(F(1,16)=18.9, p<.001\right.$, partial $\eta^{2}=0.54$ for jackknifed onsets, Figure 2A). Immediately before stimulus onset ( $750 \mathrm{~ms}$ after the cue) preparation for the high-value alternative was greater than that for the low-value alternative $(F(1,16)=17.7$, $p<.001$, partial $\eta^{2}=0.53$ ). Despite their later onset, the buildup rates of motor preparation signals for the low-value alternative were significantly steeper, (slope from 700-800 ms, $F(1,16)=9, p=.008$, partial $\left.\eta^{2}=.36\right)$. As a consequence of these differences in onset and buildup rate, the bias in relative motor preparation favouring the high-value cue peaked at around $600 \mathrm{~ms}$ post-cue and then began to decline before stimulus onset (Figure 2B). In keeping with previous observations (Kelly et al., 2020; O'Connell et al., 2012; Steinemann et al., 2018), motor preparation continued to build after stimulus onset, reaching a highly similar level at response irrespective of cue-type, coherence or regime contralateral to the chosen hand, consistent with a fixed, action-triggering threshold (Figure 2C). The left- and right-hemisphere Beta signals thus reflected two race-to-threshold motorpreparation signals, whose anticipatory buildup was indicative of dynamic urgency that, independent of the evidence, drove the signals towards the threshold (Churchland et al., 2008; Hanks et al., 2014; Murphy et al., 2016; Steinemann et al., 2018; Thura and Cisek, 2014).

Next, to trace the rapid stimulus-evoked dynamics of the decision process with higher temporal resolution we examined the broadband lateralized readiness potential (LRP). This differential signal represents the relative motor preparation dynamics between the hands associated with the correct 
and error responses (Afacan-Seref et al., 2018; Gluth et al., 2013; Gratton et al., 1988;

Noorbaloochi et al., 2015; Van Vugt et al., 2014), here examined relative to a peri-stimulus baseline interval (-50-50 ms) in order to emphasise fast stimulus-evoked dynamics (Figure 2D; see also Figure 2-Figure Supplement 1 for an analysis of the pre-stimulus LRP). Beginning approximately $100 \mathrm{~ms}$ after the stimulus, there was a deflection in the direction of the cued choice (in the correct direction for high-value trials and incorrect direction for low-value trials, $F(1,16)=20.2, p<.001$, partial $\eta^{2}=.56$, effect of value on the mean LRP from 150-180 ms, Figure 2D). We refer to this initial deflection as a "bolus," following a similar finding by Noorbaloochi et al., (2015). The sensory evidence appears to begin to affect motor preparation at around $150 \mathrm{~ms}$ when the LRP for the lowvalue trials begins to turn around and build in the correct direction.

Together these signals indicate that motor preparation passed through several key phases. Anticipatory buildup began first for the high-value alternative, followed by low-value preparation which, beginning to compensate for its lower level, reached a higher buildup rate before stimulus onset, constituting a negative drift-rate bias. Then, stimulus onset evoked a brief value-biased deflection, consistent with a positive drift-rate bias effect, before giving way to a final phase dominated by discriminatory sensory information.

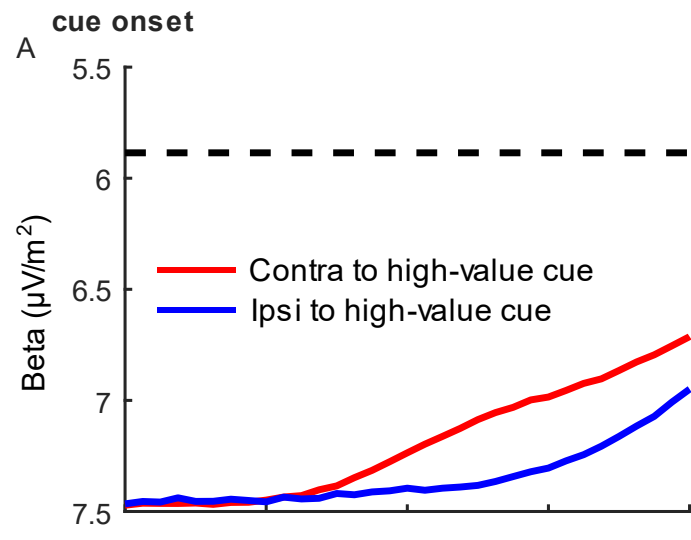

B

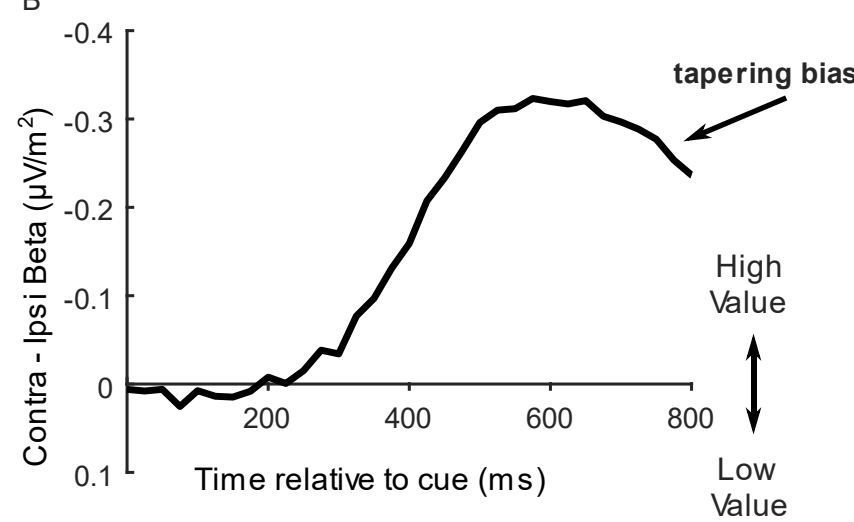

stimulus onset
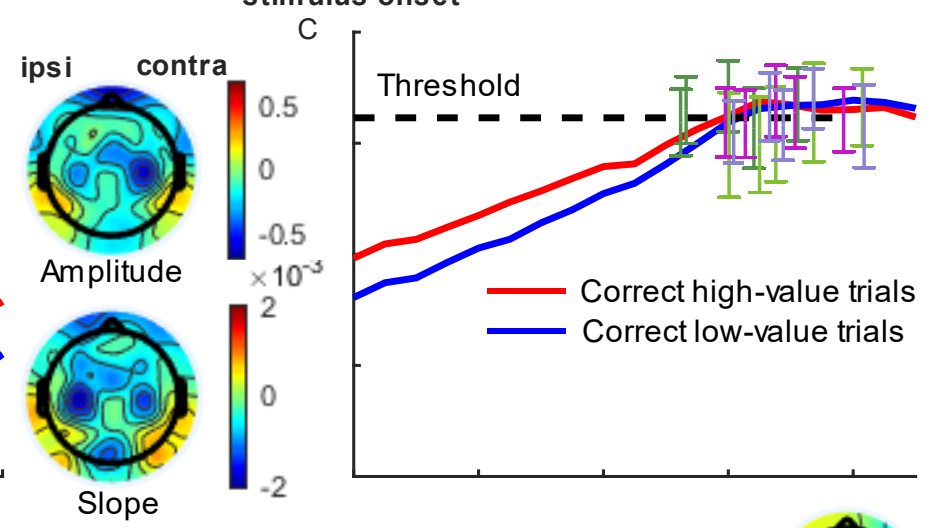

D

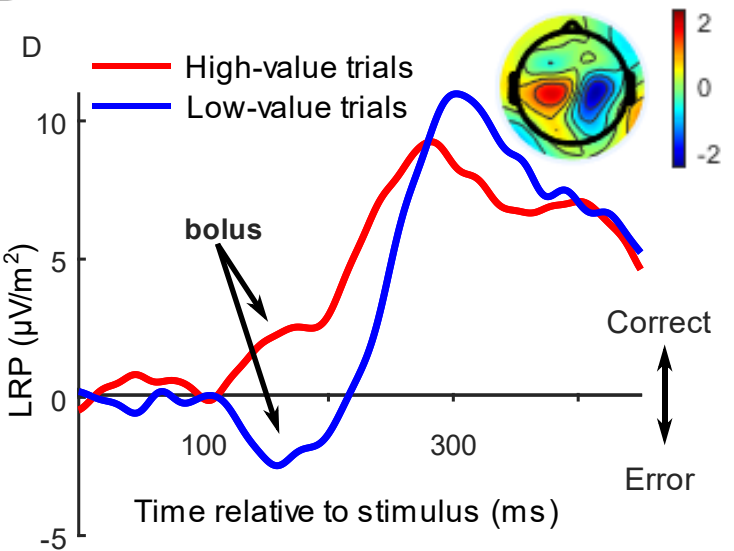

Figure 2: EEG signatures of motor preparation. A Unilateral Beta amplitude, contralateral to highand low-value alternatives in the period after the cue and before the motion stimulus appeared at 850 or $900 \mathrm{~ms}$; Note that the Y-axis is flipped such that decreasing amplitude (increasing motor preparation) is upwards. Topographies are for left-cued trials averaged with the right-left flipped topography for right-cued trials, so that the right side of the head-plot represents the hemisphere contralateral to the high-value side. Amplitude topography reflects Beta amplitude at $750 \mathrm{~ms}$ relative to amplitude at cue onset, and slope is measured from 700-800 ms. B Relative motor preparation (the difference between the waveforms in panel A), highlighting the pre-stimulus decline due to steeper low-value urgency. C Beta amplitude contralateral to response for correct trials only, relative to stimulus onset. Error bars are the standard errors of amplitudes $50 \mathrm{~ms}$ before response, with between-subject variability factored out, plotted against RT. Trials were separated by session and 
bioRxiv preprint doi: https://doi.org/10.1101/2021.03.08.434248; this version posted March 9,2021 . The copyright holder for this preprint (which was not certified by peer review) is the author/funder, who has granted bioRxiv a license to display the preprint in perpetuity. It is made available under aCC-BY 4.0 International license.

coherence, showing high- and low-value correct trials median-split by RT and low-value error trials. D LRP: ipsilateral - contralateral to correct response calculated at standard sites $C 3 / C 4$, so that deflection upward corresponds to relative motor preparation in the correct direction. LRP waveforms were baseline corrected with respect to the interval -50-50 ms to focus on local stimulus-evoked dynamics. Topography shows the difference in amplitude between left- and right-cued trials at 150$180 \mathrm{~ms}$ relative to baseline. All waveforms derived from all trials regardless of accuracy unless otherwise stated.

Model Development. We next sought to construct a decision process model that can capture both behavior and the motor preparation dynamics described above. Mimicking the unilateral Beta signals, we modeled the decision process as a race between two parallel, accumulation-to-bound decision variable (DV) signals (Figure 3A), with distinct pre-stimulus starting levels set for the DV contralateral (parameter $Z_{c}$ ) and ipsilateral $\left(Z_{i}\right)$ to the direction of the value cue for each regime. Extrapolating from the anticipatory motor preparation buildup, we assumed the operation of linearlyincreasing urgency which was also biased by the value cue. The urgency buildup rates varied from trial to trial independently for the two response alternatives, in a Gaussian distribution with means $U_{c, i}$ and standard deviation $s_{u}$. We assume in all models that the accumulation process takes an additive combination of noisy stimulus evidence plus a stimulus-evoked bias, both of which are implemented in alternative ways for comparison as detailed below. We refer to that combination as the "cumulative bias plus evidence" function, $x(t)$. The DVs were then generated by adding the cumulative bias plus evidence in favor of either alternative to the corresponding urgency signal, triggering a decision at the "decision time" when the first reached the bound:

$$
\begin{gathered}
D V_{1}(t)=D V_{1}(t-d t)+u_{1} \cdot d t+\lfloor x(t)\rfloor \\
D V_{2}(t)=D V_{2}(t-d t)+u_{2} \cdot d t+\lfloor-x(t)\rfloor
\end{gathered}
$$

Here $D V_{1}$ and $D V_{2}$ represent the DVs for the correct and incorrect responses respectively, which were updated in our simulations at a time interval $d t=1 \mathrm{~ms} . u_{1}$ and $u_{2}$ represent the urgency rates contralateral and ipsilateral to the cued direction on high-value trials, and the reverse on low-value trials. For example, in a high-value trial (in which the cued direction is the correct response):

$$
u_{1} \sim N\left(U_{c}, s_{u}\right) \text {, and }
$$

$$
u_{2} \sim N\left(U_{i}, s_{u}\right) .
$$

The cumulative bias plus evidence, $x(t)$ is positive in the direction of the correct response, and the half-wave rectification operation, $\lfloor x\rfloor=\max (0, x)$, apportions the positive and negative components to the appropriate DVs. In contrast to this approach, several authors have modeled urgency as a multiplicative "gain" function accelerating the decision process (Cisek et al., 2009; Ditterich, 2006; Evans et al., 2017; Standage et al., 2011; Thura et al., 2012). However, we considered additive motor-level urgency signals (Churchland et al., 2008; Hanks et al., 2014) that linearly increased with time (Murphy et al., 2016; Steinemann et al., 2018) to be the most natural interpretation of the Beta signals here due to their anticipatory buildup before evidence accumulation was possible.

The trial RT was obtained by adding to the decision time a motor time for motor execution; this varied from trial to trial on a uniform distribution with mean $T_{m}$ which varied between the blocked regimes, and range $s_{t}$. Allowing for regime differences in motor execution was important as its timing is known to be affected by speed/accuracy settings (Kelly et al., 2020; Rinkenauer et al., 2004; Weindel et al., in press). In previous work we had constrained the mean motor time parameter using an EEG motor-evoked potential (Kelly et al., 2020). However, likely due to the substantially increased model constraints in the current study (see Neural Constraints section below), we found in preliminary analyses that constraining the motor times in this way was detrimental to our fits. The cumulative bias plus evidence function was updated according to the following equation: 
bioRxiv preprint doi: https://doi.org/10.1101/2021.03.08.434248; this version posted March 9, 2021. The copyright holder for this preprint (which was not certified by peer review) is the author/funder, who has granted bioRxiv a license to display the preprint in perpetuity. It is made available under aCC-BY 4.0 International license.

$$
x(t)=x(t-d t)+B(t) \cdot d t+\mu(t) \cdot d t+w(t) \cdot \sqrt{d t}
$$

Here $B(t)$ represents the stimulus evoked bias, $\mu(t)$ is the drift rate of the evidence. The within-trial noise, $w(t)$, is Gaussian-distributed with standard deviation $\sigma(t)$ :

$$
w(t) \sim N(0, \sigma(t))
$$

A

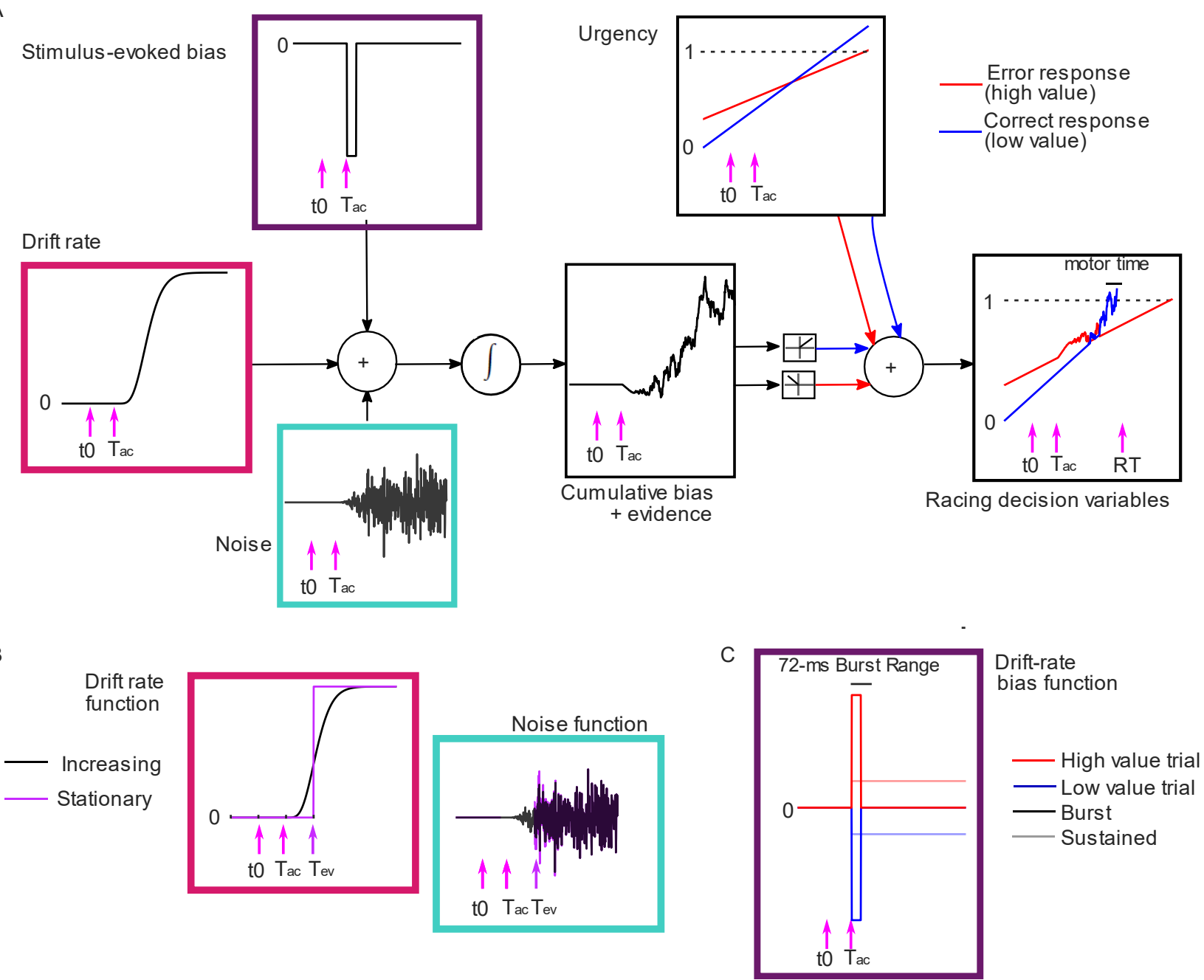

Figure 3 Model Schematic. A Components of the model with a transient burst of stimulus-evoked bias and increasing evidence ('BurstlE'), with example traces for the cumulative sum of bias plus evidence, urgency and the resultant motor-level DV traces from a simulated low-value trial. A delay $T_{a c}$ after stimulus onset, $t 0$, the combination of a sudden detection-triggered bias function and growing, noisy sensory evidence began to be accumulated, and with the addition of urgency drove the race between two DVs toward the threshold. The cumulative bias and evidence was half-wave rectified such that (positive) evidence towards the correct (low-value) response was added to the low-value urgency signal, and vice versa. B Alternative evidence and noise functions. For SE models both stepped abruptly to their asymptotic value whereas for IE models both increased according to a gamma function. C Alternative drift-rate bias functions. For 'Burst' models the duration of bias was short, with a maximum of $72 \mathrm{~ms}$, whereas sustained drift-rate bias ('Sust') 
Neural Constraints: Based on the principle that neural constraints permit greater model complexity without unduly increasing degrees of freedom (O'Connell et al., 2018), from the anticipatory motor preparation signals we adopted constraints on not just starting levels (Kelly et al., 2020) but also the biased mean urgency buildup rates. The mean Beta starting levels (750 ms post cue) and slopes (from 700-800 ms post-cue) were calculated for each regime across participants. To obtain the model parameters, we linearly re-scaled the Beta signals within a range from 0 , corresponding to the lowest starting level, to a fixed bound of 1 corresponding to the Beta threshold-the average value of Beta contralateral to the chosen hand across all conditions $50 \mathrm{~ms}$ prior to response (see Figure 4A). The starting levels and mean rates of urgency buildup for the high and low-value alternatives were set to equal the amplitude and temporal slope of the corresponding scaled Beta signals for each regime (Table 1).

Table 1: EEG-constrained parameters.

\begin{tabular}{|l|l|l|l|l|}
\hline Parameter & Symbol & $\begin{array}{l}\text { High } \\
\text { Coherence }\end{array}$ & $\begin{array}{l}\text { Low } \\
\text { Coherence }\end{array}$ & Interleaved \\
\hline Starting point contralateral to high value & $Z_{c}$ & .32 & .3 & .2 \\
Starting point ipsilateral to high value & $Z_{i}$ & .12 & .002 & 0 \\
Mean urgency rate contralateral to high value & $U_{c}$ & 1.36 & 1.09 & 1.3 \\
Mean urgency rate ipsilateral to high value & $U_{i}$ & 1.83 & 1.7 & 1.79 \\
\hline
\end{tabular}

Within this neurally-constrained urgency model framework, we fit several alternative bounded accumulation models to the data for comparison. It has already been established by several researchers that the behavioral patterns in fast value-biased decisions are not well-captured by standard accumulation-to-bound models with stationary drift rates (Afacan-Seref et al., 2018; Diederich and Busemeyer, 2006; Noorbaloochi et al., 2015). For this reason, we have not compared the performance of our neurally-informed models to these standard models (although see Kelly et al., (2020) for a comparison between the diffusion decision model and a related neurally-informed model). Instead, we restricted our analysis to models that can capture motor preparation dynamics-namely the strong empirical signatures of anticipatory urgency-as well as behavior, and thus provide a more detailed parsing of multiple biasing phases. With this structure common to all models, we explored whether the data were better captured by a stationary (Ratcliff and McKoon, 2008) or growing (Afacan-Seref et al., 2018; Smith and Lilburn, 2020) evidence function, and by a sustained (Afacan-Seref et al., 2018) or transient (Diederich and Busemeyer, 2006) drift-rate bias, by comparing four main model variants that featured two plausible alternative ways to implement noisy evidence accumulation and two different stimulus-evoked biasing mechanisms:

\section{Evidence and noise functions: We compared models with a standard stationary evidence (SE)} function with abrupt onset to increasing evidence (IE) models where the evidence and noise gradually grow with time (Smith et al., 2014; Smith and Lilburn, 2020) (Figure 3B). Both model types had an asymptotic drift rate parameter, $v$, to which the mean of the sensory evidence stepped (SE) or gradually tended (IE), for each coherence level. A single within-trial noise parameter $(s)$ dictated the asymptotic standard deviation of Gaussian-distributed within-trial noise. We also estimated an onset time for accumulation, $T_{a c}$, relative to stimulus onset. In the SE models this parameter signalled the onset of the bias accumulation (see below), while the noisy evidence stepped up at a later time, $T_{e v}$ :

$$
\begin{aligned}
& \mu_{S E}(t)=\left\{\begin{array}{l}
v \text { if } t>T_{e v} \\
0 \text { otherwise }
\end{array}\right. \\
& \sigma_{S E}(t)=\left\{\begin{array}{l}
s \text { if } t>T_{e v} \\
0 \text { otherwise }
\end{array}\right.
\end{aligned}
$$

In the IE models, the bias, evidence and noise functions all began at $T_{a c}$. The increasing evidence and noise functions used were those developed for a time-changed diffusion model (Smith et al., 2014; Smith and Lilburn, 2020) in which the drift rate $v$, and diffusion coefficient $s^{2}$ (the squared 
bioRxiv preprint doi: https://doi org/10.1101/2021.03.08.434248; this version posted March 9,2021 . The copyright holder for this preprint (which was not certified by peer review) is the author/funder, who has granted bioRxiv a license to display the preprint in perpetuity. It is made available under aCC-BY 4.0 International license.

standard deviation of the Gaussian-distributed within-trial noise), are both scaled by a growth rate function $\vartheta$ :

$$
\begin{gathered}
\mu_{I E}(t)=v \cdot \vartheta(t) \\
\sigma_{I E}(t)=s \cdot \sqrt{\vartheta(t)}
\end{gathered}
$$

Following Smith and Lilburn (2020, see equation 9), $\vartheta$ took the form of an incomplete gamma function with rate $\beta$, where the argument $n$ and $\beta$ were free parameters:

$$
\vartheta(t)=\left\{\begin{array}{c}
\frac{1}{\Gamma(n)} \int_{0}^{\beta\left(t-T_{a c}\right)} e^{-r} r^{n-1} d r, \text { if } t>T_{a c} \\
0 \text { otherwise }
\end{array}\right.
$$

In this equation $\Gamma(n)$ is the gamma function. The shape of the function obtained by one of our model fits is shown in Figure 3B.

Stimulus-evoked bias functions: We also compared two alternative implementations of a drift-rate bias across different model variants. One featured a sustained drift-rate bias ('Sust') which began at $T_{a c}$ and lasted until response. The other featured a shorter transient bias, inspired by the apparent concentrated burst of value-biased activity ('Burst') before evidence accumulation took hold in the LRP (Figure 3C). Both of these functions involved a bias magnitude parameter $\left(v_{b}\right)$ for each regime:

$$
\begin{gathered}
B_{\text {Sust }}(t)=\left\{\begin{array}{c} 
\pm v_{b} \text { if } t \geq T_{a c} \\
0 \text { otherwise }
\end{array}\right. \\
B_{\text {Burst }}(t)=\left\{\begin{array}{c} 
\pm v_{b} \text { if } T_{a c} \leq t \leq\left(T_{a c}+\text { Burst } T\right) \\
0 \text { otherwise }
\end{array}\right.
\end{gathered}
$$

The bias factor $\pm v_{b}$ was positive for high-value trials and negative for low-value trials. The 'Burst' was composed of a drift-rate bias beginning at $T_{a c}$ whose duration BurstT varied on a uniform distribution from $0-72 \mathrm{~ms}$. In preliminary analyses we found that the burst magnitude and its range of durations could trade off each other such that equivalent fits to behavior could be found for a wide range of values of the latter. We thus fixed the maximum duration to $72 \mathrm{~ms}$ because it produced a simulated-DV bolus similar in duration to the real LRP (Figure 4 B,C; see Methods). We also restricted $T_{a c}$ to a narrow range of $90-100 \mathrm{~ms}$ in the fits, close to the apparent onset of the real LRP bolus; we did not find that expanding this range helped the models to converge.

Model Fits. Models were fit to the group average of the RT quantiles (see Methods). The increasing-evidence (IE) models performed better than the stationary-evidence (SE) models, with the BurstlE model providing the best fit to behavior (Table 2). This model captured all the main qualitative features of the RT distributions, including the indistinguishable (value-driven) leading edges of correct high-value and incorrect low-value trials (Figure $4 \mathrm{D}-\mathrm{E}$ ), and the transition from value-based to evidence based responses visible in the low-value conditional accuracy functions (CAFs, Figure 4F). Although the SustlE, BurstSE and SustSE models exhibited a less close quantitative fit to behavior as reflected in Akaike's Information Criterion (AIC), qualitatively, they all captured the main behavioral patterns reasonably well including the biased fast guess responses (Figure 4-Figure Supplements 1-3). The estimated parameters for these four primary models are given in Table 3.

We tested four additional versions of the IE model to assess the contribution of the constrained urgency and stimulus-evoked bias to the fits (Table 2). First, allowing the urgency rates to be free parameters, but unbiased by value (Kelly et al., 2020), did not capture the behavior as well as the 
bioRxiv preprint doi: https://doi org/10.1101/2021.03.08.434248; this version posted March 9,2021 . The copyright holder for this preprint (which was not certified by peer review) is the author/funder, who has granted bioRxiv a license to display the preprint in perpetuity. It is made available under aCC-BY 4.0 International license.

constrained IE models. Then, a model with constrained urgency but no stimulus-evoked bias produced a far inferior fit. These results suggest that in addition to accounting for the slow temporal integration properties of sensory evidence encoding, incorporating both key insights gained from the EEG signals was critically important in capturing behavior. We then verified the specific contribution of quantitative differences across regimes in the urgency effects measured in the Beta signals by showing that swapping the neural constraints across regimes substantially worsened the fit. Finally, in Table 2- Table Supplement 1 we report the performance of selected models that incorporate additional parameters - such as a 'drift boost' under speed pressure and starting-level variabilitywhich were included in a neurally-informed model from previous work (Kelly et al., 2020) but had little effect here.

Table 2. Goodness of fit metrics.

\begin{tabular}{|l|l|l|l|l|l|}
\hline Model & Stimulus-evoked bias & Evidence & $\mathrm{k}$ & $\mathrm{G}^{2}$ & $\mathrm{AIC}$ \\
\hline BurstIE & Burst & Increasing & 14 & 39 & 67 \\
SustlE & Sustained & Increasing & 14 & 51 & 79 \\
BurstSE & Burst & Stationary & 13 & 62 & 88 \\
SustSE & Sustained & Stationary & 13 & 87 & 113 \\
Unbiased urgency slopes & Burst & Increasing & 17 & 54 & 88 \\
Urgency-only bias & None & Increasing & 11 & 351 & 373 \\
Constraints-Swap 1 & Burst & Increasing & 14 & 250 & 278 \\
Constraints-Swap 2 & Burst & Increasing & 14 & 111 & 139 \\
\hline
\end{tabular}

Goodness of fit quantified by chi-squared statistic, $G^{2}$. Model comparison was performed using Akaike's Information Criterion (AIC), which penalises for the number of free parameters $(\mathrm{k})$. In the two Constraints-Swap models, the constrained parameters for $A)$ high coherence, $B$ ) low coherence and $C$ ) interleaved blocks were taken from the neural signals corresponding to $[B, C, A](S w a p$ 1) and $[C, A, B]($ Swap 2), respectively.

A
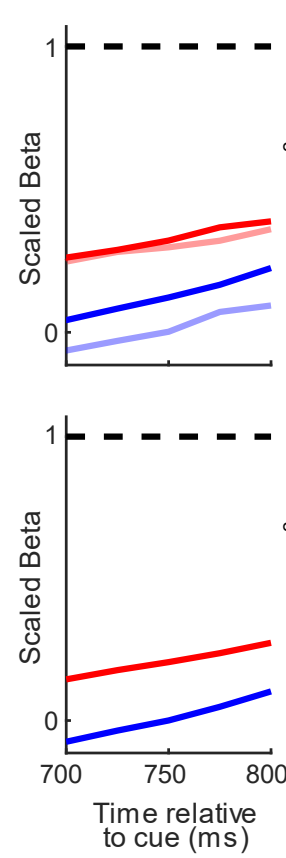

B
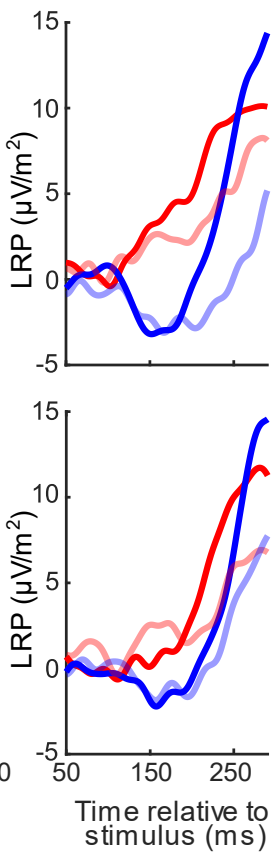

High value High coherence Low coherence

C
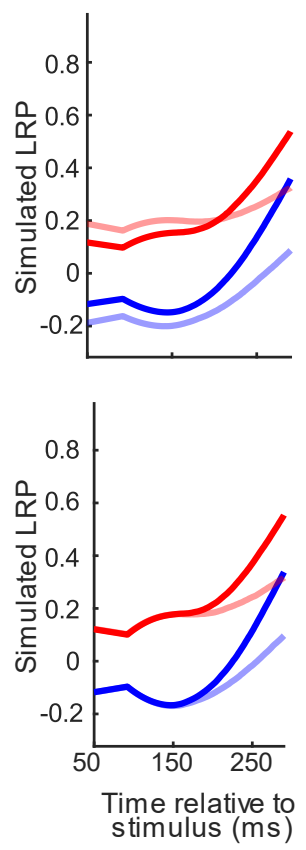

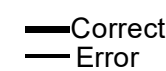

D
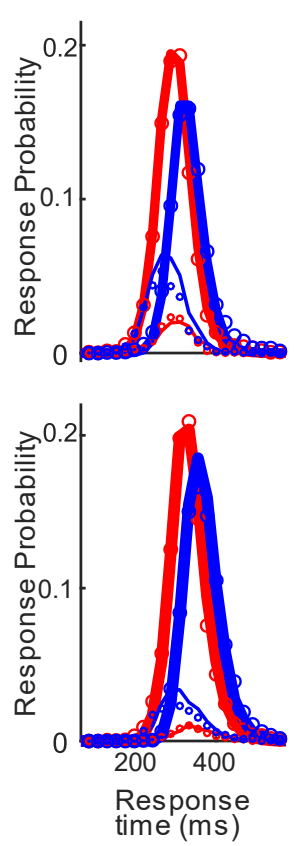

E
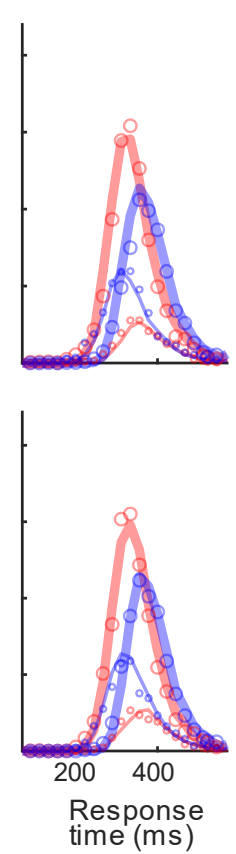

$\mathrm{F}$
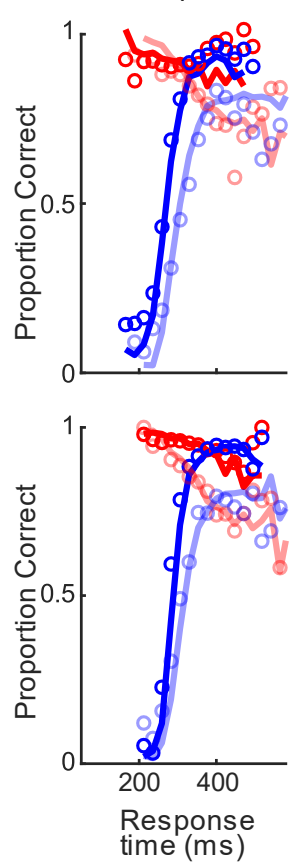

Figure 4: Real and model-simulated waveforms and behavior for blocked session (top row) and interleaved session (bottom row). A Scaled Beta signals used to constrain the models. The high 
versus low-value difference in starting level varied across regime (Regime $x$ Value interaction $\mathrm{F}(2,32)=4.2, \mathrm{p}=.03$, partial $\eta^{2}=.87$; pairwise comparisons of value-difference indicated low coherence blocked $>$ high coherence blocked, $p=0.01)$. The Regime $\times$ Value interaction for slope was not statistically significant $\left(F(2,32)=0.29, p=.74\right.$, partial $\left.\eta^{2}=.96\right)$; B Real LRP. There was a significant interaction in bolus amplitude (mean LRP from 150-180 ms) between Value and Condition $\left(F(3,48)=3.4, p=.03\right.$, partial $\eta^{2}=.86$, but pairwise comparisons of the value difference indicated no significant differences between conditions (all $p>0.15$ ). C Mean simulated trajectories of the difference between correct and incorrect DVs from the best-fitting model with Burst drift-rate bias and increasing evidence (BurstIE); D-E Real (circles) and model-simulated (solid lines) RT distributions. F Real and model-simulated conditional accuracy functions (CAFs). All waveforms derived from all trials regardless of accuracy.

Table 3: Estimated parameters for the four main models.

\begin{tabular}{|l|l|l|l|l|l|}
\hline Parameter & Symbol & BurstlE & SustlE & BurstSE & SustSE \\
\hline Asymptotic drift rate (high coherence) & $v_{h}$ & 5.8 & 6.6 & 4.5 & 5.0 \\
Asymptotic drift rate (low coherence) & $v_{l}$ & 2.6 & 2.9 & 2.0 & 2.2 \\
Drift rate bias (high coherence blocked) & $v_{b h}$ & 2.3 & .54 & 2.4 & 0.58 \\
Drift rate bias (low coherence blocked) & $v_{b l}$ & 2.1 & .43 & 2.3 & 0.48 \\
Drift rate bias (interleaved) & $v_{b i}$ & 2.9 & .6 & 3.0 & 0.66 \\
Within-trial noise asymptotic standard deviation & $S$ & 1.0 & 0.95 & 0.85 & 0.82 \\
Accumulation onset time (ms) & $T_{a c}$ & 93 & 92 & 99 & 94 \\
Burst duration range (ms) & $b_{r a n g e}$ & 72 & --- & 72 & ---- \\
$\vartheta(t)-$ rate & $\beta$ & 61.7 & 34.9 & --- & -- \\
$\vartheta(t)-$ argument & $n$ & 7.5 & 6.2 & --- & --- \\
Evidence onset time (ms) & $T_{e v}$ & --- & --- & 210 & 220 \\
Mean motor time (high coherence blocked) (ms) & $T_{m h}$ & 81 & 56 & 67 & 60 \\
Mean motor time (low coherence blocked) (ms) & $T_{m l}$ & 82 & 50 & 66 & 60 \\
Mean motor time (interleaved) (ms) & $T_{m i}$ & 92 & 61 & 77 & 70 \\
Urgency rate variability & $S_{u}$ & 0.43 & 0.39 & 0.38 & 0.42 \\
Motor time variability (ms) & $S_{t}$ & 57 & 53 & 77 & 86 \\
\hline
\end{tabular}

Note: Fixed parameter shown in bold typeface.

Decision Variable Simulations. We qualitatively explored the correspondence between the fast neural dynamics of the LRP and simulated decision process by plotting the difference between the two DVs (Figure 4 B-C). The starting levels are not comparable because, unlike the simulated process, the real LRP was baseline corrected, and the initially decreasing value bias in the simulated waveforms is not seen in the LRP due to interfering posterior slow potentials (see Figure 2-Figure Supplement 1). There was, however, good correspondence between the dynamics from the onset of the deflection, which was notably absent in the alternative SustIE and SustSE model simulations (Figure 4-Figure Supplements 1,3). The BurstlE model effectively captured aspects of both EEG motor preparation signatures through its distinct countervailing biasing mechanisms.

\section{Discussion}

Convergent evidence from motor preparation signals and behavioral modeling demonstrated that a dynamic sequence of opposing value biases and non-stationary evidence accumulation all played important roles in forming the rapid, multiphasic decisions on this task. In most decision-making models a "starting-point bias" parameter-shifting the starting point of accumulation-treats anticipatory biases as static adjustments before the process begins (Leite and Ratcliff, 2011; Mulder et al., 2012). Here, far from creating a stable starting point to kick off a stationary decision process, we found a dynamic pattern of biased motor preparation that is best understood as a twodimensional race beginning well in advance of the stimulus. Constraining a behavioral model with 
bioRxiv preprint doi: https://doi.org/10.1101/2021.03.08.434248; this version posted March 9,2021 . The copyright holder for this preprint (which was not certified by peer review) is the author/funder, who has granted bioRxiv a license to display the preprint in perpetuity. It is made available under aCC-BY 4.0 International license.

these signals enabled us to characterise a surprisingly complex process, revealing biasing mechanisms that would otherwise have been inaccessible.

In agreement with previous research that has called for nonstationary accounts of value biasing in time-pressured decisions (Diederich and Busemeyer, 2006), we found that the value bias was largely concentrated in the early part of the process. The particular dynamics of the RDK stimulus, featuring a substantial lag between stimulus onset and the emergence of discriminatory sensory evidence, may have provided a focal point for the bias to be expressed separately from the evidence itself. However, the signature expressions of this sequential detection-discrimination effect-namely, the almost purely value-driven nature of both the leading edge of RT distributions and of the initial stimulus-evoked LRP deflection-are observed also for discriminations of stimulus displacement (Noorbaloochi et al., 2015) and color (Afacan-Seref et al., 2018), suggesting the phenomenon generalises beyond the RDK stimulus. While our findings indicate that a strong transient drift-rate bias better captures the data relative to a sustained, constant bias, the possibility of a hybrid of the two, where the initial detection-triggered burst reduces to a smaller sustained bias, was not tested because it was assumed to go beyond a reasonable number of free parameters. Thus, uncertainty remains regarding the exact temporal profile of this stimulus-evoked bias, and we cannot say that it fully disappears beyond the burst.

The implication of a negative "drift-rate" bias in urgency is counterintuitive but not completely without precedent. In the context of the diffusion decision model with unequal prior probabilities, Moran (2015) found that a negative drift-rate bias featured alongside a starting point bias in the optimal decision strategy under certain assumed bound settings, albeit not when bound settings were assumed controllable as part of the optimization calculation. Here, a similar tradeoff between the positive starting-level bias and negative urgency-rate bias may have arisen from the fact that the greater the starting point bias, the greater the need for a steeper low-value urgency signal to give it a chance to overtake the high-value signal when the low-value DV represents the correct response.

Understanding the processes generating the behaviors in this task rested on the neurophysiological identification of strategic urgency biases. The anticipatory nature of the early Beta signal buildup aided in specifically linking it to evidence-independent urgency, and its incorporation in the model was key to understanding the subsequent processing of the motion stimulus. The most significant disadvantage of relying on group-average neurophysiology to constrain our model, however, was that we were unable to examine individual differences in behavior. The extent to which these different forms of bias might trade off each other at the individual level remains for now an open question. Nevertheless, the finding of a negative urgency rate bias as part of the participants' dominant strategy highlights the broad range of dynamic adjustments that can be made in the course of fast-paced sensorimotor decisions.

\section{Methods}

Participants. The experiment involved one psychophysical training session and two EEG recording sessions. As the task was challenging, the training session served a dual purpose of giving participants the time to learn the task and to screen out those who found it too difficult. Twenty-nine adult human participants performed the training session. Eleven discontinued who either did not sufficiently improve to the point of being able to perform the task well, or chose to do so due to having other commitments. Eighteen participants ( 8 female) thus completed the two EEG sessions. Motor preparation biasing effects tend to be consistent and robust (e.g. effect sizes of at least $\mathrm{d}=1$ for similar "bolus" effects in Afacan-Seref et al., 2018), and 15-18 participants provide $80 \%$ power to detect medium-to-large effect sizes. Participants all had normal or corrected-to-normal vision. They each provided informed, written consent to the procedures, which were approved by the Ethics Committee of the School of Psychology at Trinity College Dublin, and the Human Research Ethics Committee for the Sciences, at University College Dublin. Participants were compensated with €20 for the training session and $€ 32$ for their participation in each EEG session with the potential to earn 
bioRxiv preprint doi: https://doi.org/10.1101/2021.03.08.434248; this version posted March 9,2021 . The copyright holder for this preprint (which was not certified by peer review) is the author/funder, who has granted bioRxiv a license to display the preprint in perpetuity. It is made available under aCC-BY 4.0 International license.

408 up to $€ 12$ further depending on their performance. One of the participants was an author and the 409 remainder were naive.

410 Setup. Participants were seated in a dark booth, with their heads stabilized in a chin rest placed 57 $\mathrm{cm}$ from a cathode ray tube monitor (frame rate $75 \mathrm{~Hz}$, resolution $1024 \times 768$ ) with a black background. They rested their left/right thumbs on the left/right buttons of a symmetric computer mouse secured to the table in front of them.

Task. The task was programmed in Psychtoolbox for MATLAB (Brainard, 1997). Trials began with the presentation of a central grey $0.25^{\circ}$ fixation square. Upon achieving fixation ( $4^{\circ}$ radius detection window, EyeLink 1000, SR Research), a value cue replaced the fixation square after either 400 or $450 \mathrm{~ms}$ (randomly selected) and remained on screen, until the end of the trial (Figure 1). The cue consisted of equiluminant green and cyan arrows placed and pointing to the left and right of center, indicating the directions that would be worth 30 points (high value) or 10 points (low value) if subsequently presented and correctly responded to with the corresponding hand within the deadline. Incorrect or late responses were worth 0 points. Color-value assignment was randomly counterbalanced across participants. The RDK stimulus ( $5^{\circ}$ diameter) appeared and commenced moving either 850 or $900 \mathrm{~ms}$ (randomly selected) after cue onset and lasted 600 or $781 \mathrm{~ms}$ for the shorter or longer deadline conditions, respectively. Participants were required to maintain fixation throughout, and upon stimulus offset received feedback on whether they were 'Correct!', 'WRONG!', 'TOO SLOW!' or 'TOO EARLY! WAIT FOR CUE ...' and on the total points, and the number of points missed for each trial type (blue and green), at the end of each block.

The task was performed in three blocked regimes: High coherence (51.2\%) with a short deadline (365 ms); low coherence (19.2\%) with a slightly longer deadline (475 ms); and interleaved high and low coherence with the longer deadline. The RDK stimulus was adapted from code from the Shadlen laboratory (Gold and Shadlen, 2003; Roitman and Shadlen, 2002). A set of white dots were presented within a circular aperture of $5^{\circ}$ in diameter that was the same black color as the background. The dot density was 16.7 dots per $\%$. One third of the total number of dots was visible on screen at any one time; each dot remained on screen for one 13.3-ms frame and was replotted 2 frames later as the 3 sets of dots were alternated. Depending on the coherence level, each dot had either a $19.2 \%$ or $51.2 \%$ chance of being replotted by an offset in the direction of coherent motion at a rate of $5 \%$ s. Otherwise the dots were randomly relocated within the aperture. The first onset of coherent motion thus occurred $40 \mathrm{~ms}$ ( 3 frames) after the onset of the stimulus. If an offset dot was set to be plotted outside of the aperture, it was replotted in a random location on the edge of the aperture opposite to the direction of motion.

Procedure. So that participants could become familiar with the task, and particularly get used to its fast pace, they performed one session of psychophysical training before the main experimental sessions. Blocks in the training sessions comprised 80 trials. The session began with blocks of highcoherence trials with a long deadline and without value bias (20 points for each direction; both arrow cues were yellow). The deadline was gradually reduced to $365 \mathrm{~ms}$. The same procedure was then followed for low-coherence blocks. If participants had great difficulty with the low coherence, the experimenter gave them some further practice starting at $45 \%$ and gradually brought it down to $19.2 \%$. Finally, participants practiced an equal number of biased blocks in the high-coherence, lowcoherence, and interleaved high- and low-coherence regimes.

Participants performed the two blocked regimes ( 5 or 6 blocks each of 120 trials) in one EEG recording session and the interleaved regime (10 or 12 blocks) in the other. Due to experimenter error, one participant performed the blocked experimental session twice and we included the data from both sessions in our analyses. The blocks within each regime were run consecutively to ensure that subjects would settle into a strategy, and the order of regimes and sessions was randomized. In training and throughout the EEG recording sessions, participants were encouraged to adopt a strategy that would maximise their points and were informed that the points earned in two randomly selected blocks (one per regime in the blocked session) would determine their bonus payment in 
bioRxiv preprint doi: https://doi org/10.1101/2021.03.08.434248; this version posted March 9,2021 . The copyright holder for this preprint (which was not certified by peer review) is the author/funder, who has granted bioRxiv a license to display the preprint in perpetuity. It is made available under aCC-BY 4.0 International license.

459 each recording session. Participants were provided with the total number of points earned at the 460 end of the block as well as the number of points missed in the block for each trial type (blue and 461 green), to motivate them and help them determine whether they were biasing too much or too little. 462 The experimenters helped participants interpret this feedback and when needed provided frequent there were no points awarded for late responses.

Behavioral analyses. RTs were measured relative to the onset of the RDK stimulus. RTs less than $50 \mathrm{~ms}(0.23 \%$ of trials) were excluded from behavioral analyses and model fitting. Responses up to and beyond the deadline were included in all analyses so long as they occurred before the end of the RDK stimulus; trials without a response $(0.21 \%$ of trials) were excluded. One participant was an outlier in terms of biasing (error rate difference between low-value and high-value trials fell more than two interquartile ranges above the upper quartile) and was excluded from further analyses.

\section{Electrophysiological data analysis. Continuous EEG data from 128 scalp electrodes were} acquired using an ActiveTwo system (BioSemi, The Netherlands) and digitized at $1024 \mathrm{~Hz}$. Offline analyses were performed using in-house MATLAB scripts (MathWorks, Natick, MA) using data reading, channel interpolation and topographic plot functions from the EEGLAB toolbox (Delorme and Makeig, 2004). EEG data were low-pass filtered by convolution with a 137-tap hanningwindowed sinc function designed to provide a 3-dB corner frequency of $37 \mathrm{~Hz}$ with strong attenuation at the mains frequency $(50 \mathrm{~Hz})$, detrended and average referenced. The data were epoched from -150 to 2450 ms relative to the cue onset. We identified and interpolated (spherical splines) channels with excessively high variance with respect to neighboring channels and channels that saturated or flat-lined during a given block. Trials were rejected upon detection of artifacts between cue and response (on selected frontal channels sensitive to blinks with magnitude $>70 \mu \mathrm{V}$, or $50 \mu \mathrm{v}$ for the selected motor channels used in our analyses). Then, to mitigate the effects of volume conduction across the scalp, current source density (CSD) transformation was applied to the single-trial epochs (Kayser and Tenke, 2006; Kelly and O'Connell, 2013). Shorter cue-locked (-150 to $1500 \mathrm{~ms})$, stimulus-locked $(-1000$ to $650 \mathrm{~ms})$ and response-locked $(-400$ to $210 \mathrm{~ms})$ event-related potentials (ERPs) were then extracted from the longer epochs, and baseline corrected to the 100ms window following the cue. The LRP was calculated as the difference in ERP between electrodes at standard 10-20 sites C3 and C4 (Gratton et al., 1988), by subtracting the ERP ipsilateral to the correct response from the contralateral ERP.

Beta-band activity was measured using a short-time Fourier transform applied to 300-ms windows stepped by $25 \mathrm{~ms}$ at a time, and by taking the mean amplitude in the range $14-30 \mathrm{~Hz}$. We restricted our measurements to the Beta band as opposed to including both Mu and Beta (Kelly et al., 2020) to avoid any potential interference from posterior Alpha-band activity which is known to lateralise in situations where attention can be guided to the left or right. We found posterior lateralization to be minimal in the Beta-band amplitude, and while there was an appreciable slope difference this was clearly separated from the motor-related areas (see Figure 5A). To ensure precise measurements for model constraints, Beta was measured from electrodes selected per individual based on exhibiting the strongest decrease at response relative to cue or stimulus onset. Standard sites C3/C4 were selected by default where difference-topography foci were close and symmetric (9 of 17 subjects), and otherwise electrodes were selected among those proximal to the foci based on their exhibiting smooth decline in their amplitude timecourses from cue to response. Where uncertain, preference was given to symmetry across hemispheres and electrodes that reached a common threshold across conditions at response.

For these individually-selected electrodes (marked in Figure $5 \mathrm{~A}$ ), the contralateral beta just prior to response $(-50 \mathrm{~ms})$ reached a threshold across conditions (Figure $5 \mathrm{~B}$; the error bars in Figure $2 \mathrm{C}$ break this down further into value and response conditions). The ipsilateral Beta diverged between the blocked high coherence and the other conditions, indicating a closer race for the most speedpressured condition. When the standard C3/C4 sites were instead selected, however, we found an offset between the blocked conditions and the interleaved conditions (Figure 5C). This was 
bioRxiv preprint doi: https://doi.org/10.1101/2021.03.08.434248; this version posted March 9, 2021. The copyright holder for this preprint (which was not certified by peer review) is the author/funder, who has granted bioRxiv a license to display the preprint in perpetuity. It is made available under aCC-BY 4.0 International license.

unexpected, but not entirely surprising due to the fact that the blocked and interleaved sessions were performed on different days for all participants, and the different demands potentially resulted in some global changes in measured Beta amplitude not directly related to motor preparation. The inset topographies show the overall difference in Beta amplitude between the two sessions at response; the difference does not appear to be of motor origin. As this difference was evident to a similar degree before the stimulus onset, we recalculated the Beta starting points and slopes with the $\mathrm{C} 3 / \mathrm{C} 4$ electrodes after first subtracting the offset between the two sessions at $-50 \mathrm{~ms}$ from response from all Beta traces. We found that the calculated neural constraints were similar regardless of electrode choice (Figure 5-Supplementary Table 1). The starting levels were almost identical except for a small difference in the low-coherence-blocked levels both contralateral and ipsilateral to high value. The steeper ipsilateral slope was also maintained and the difference relative to contralateral slope had a similar magnitude. Due to our desire to obtain the clearest view of motor activity possible, we used the individually-selected electrodes in our modeling and analyses.

A
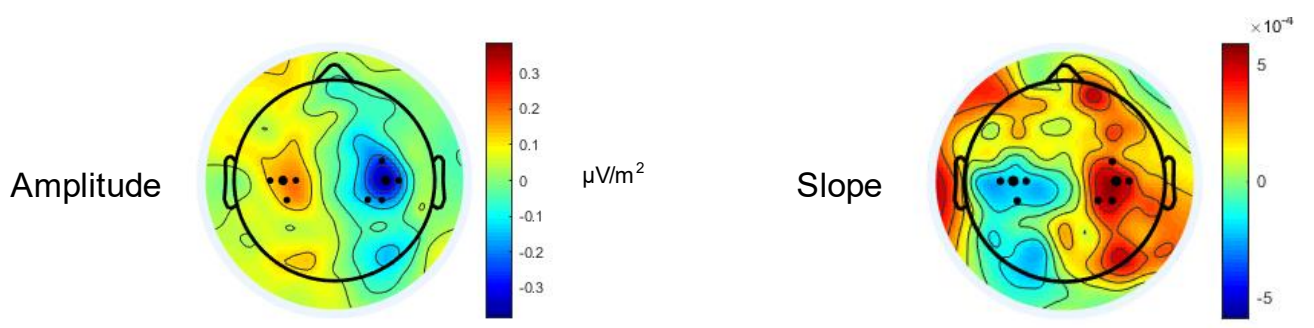

B

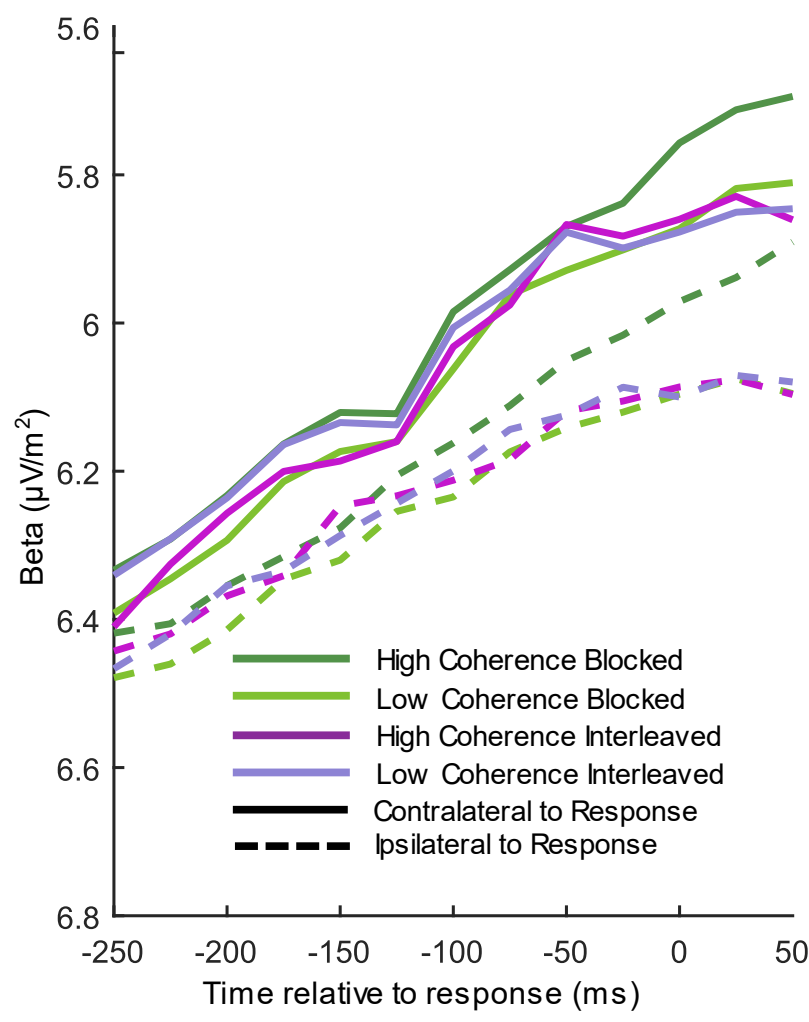

C Left responses

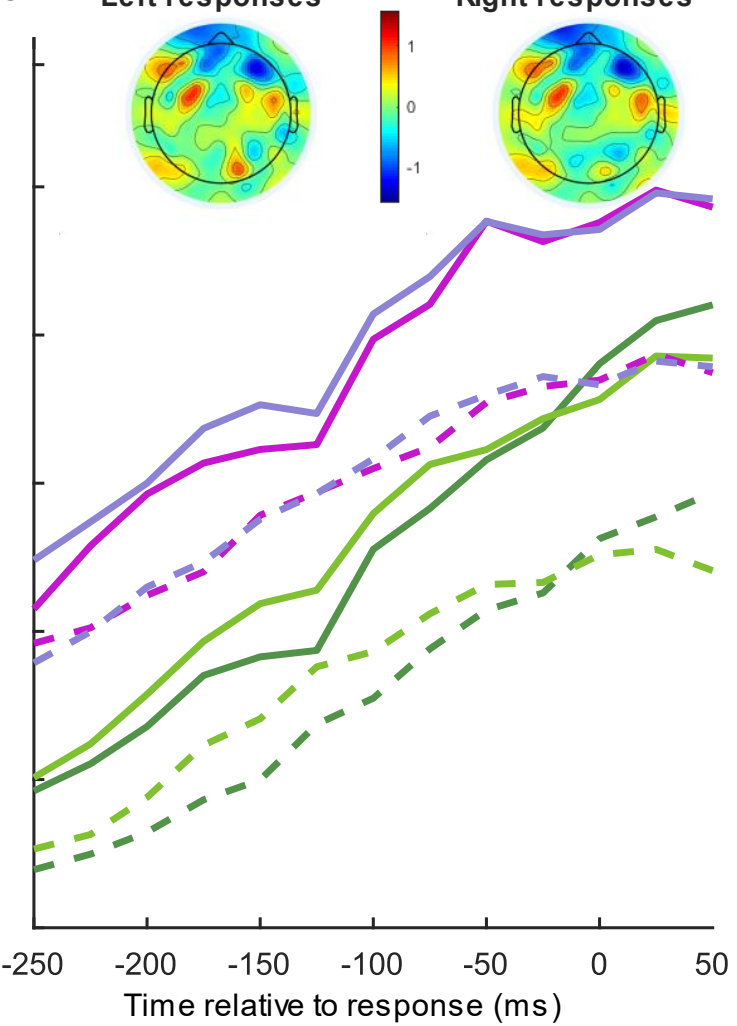

Figure 5 Electrode selection for Beta analysis. A Topographies of the difference between left- and right-cued trials for Beta amplitude at $750 \mathrm{~ms}$ relative to amplitude at the cue, and slope from 700800 ms after the cue. Standard sites C3/C4 are marked with large black dots, while other electrodes that were selected for certain individuals are marked with smaller dots. B Response-locked Beta contralateral (solid) and ipsilateral (dashed) to response for the four conditions with individually selected electrodes. C Same as B, but with standard sites C3/C4 selected for all participants. 
bioRxiv preprint doi: https://doi.org/10.1101/2021.03.08.434248; this version posted March 9,2021 . The copyright holder for this preprint (which was not certified by peer review) is the author/funder, who has granted bioRxiv a license to display the preprint in perpetuity. It is made available under aCC-BY 4.0 International license.

Topographies show the average difference in Beta amplitude between blocked and interleaved conditions at $-50 \mathrm{~ms}$ relative to response, for right and left responses separately.

Statistical Approach. Repeated measures ANOVAs with both Value and Regime/Conditions included as appropriate, were used to test for differences in behavioral and neural amplitude and slope measures, and followed up with pairwise, FDR-corrected t-tests. Given the study's focus on mechanisms common to the various conditions, we state main effects of value in the main text, and address regime effects in the figure legends. The onsets for the Beta signals were calculated using a jackknife procedure in which the traces were computed for the average signals of 16 subjects at a time, with each subject systematically excluded in turn, to compute the first time at which it exceeded $20 \%$ of the response threshold for that subgroup. The standard errors of each condition were then scaled up by 16 and a repeated-measures ANOVA was conducted.

Modeling. We fit each model to 16 RT distributions (Figure 4 D-E): correct and error responses for high- and low-value trials across the four conditions. We partitioned each distribution into 6 bins bounded by the $0.1,0.3,0.5,0.7$ and 0.9 quantiles. Models were fit by minimising the chi-squared statistic $G^{2}$, between the real quantiles and those obtained from Monte-Carlo simulated RT distributions:

$$
G^{2}=2\left(\sum_{c=1}^{4} \sum_{v=1}^{2} N_{c, v}\left[\sum_{o=1}^{2} \sum_{q=1}^{6} p_{c, v, o, q} \log \frac{p_{c, v, o, q}}{\pi_{c, v, o, q}}\right]\right)
$$

where $p_{c, v, o, q}$ and $\pi_{c, v, o, q}$ are the observed and predicted proportions of responses in bin $\mathrm{q}$, bounded by the quantiles, of outcome o (correct/error) of condition $c$ (coherence $\mathrm{x}$ Blocked/Interleaved) and value $v$ (high/low), respectively. $N_{c, v}$ is the number of valid trials per condition and value.

In the model simulations the urgency signals were defined to equal their scaled (750 ms post-cue) Beta levels at $100 \mathrm{~ms}$ prior to stimulus onset time. In the experiment, stimulus onset corresponded to 850 or 900 ms post cue; thus, we started the stimulus-evoked accumulation with a 50-ms delay on half of the trials and adjusted the RTs accordingly. For the IE models, the shape function $\vartheta(t)$ was obtained in our simulations by numerical integration. We searched the parameter space using the particle swarm optimization algorithm (Kennedy and Eberhart, 1995) as implemented in MATLAB, initialized with a number of swarms equal to 10 times the number of parameters to be estimated. To aid convergence we set the same random seed for each simulation within a search, which comprised 20,000 trials per value per condition. Because there was randomness associated with the optimization we ran it at least 3 times for each model. We followed this with a call to fminsearchbnd (Nelder and Mead, 1965) initialized with each of the parameter estimates for the model and any nested models, to obtain a second set of parameter estimates. We then obtained a final $G^{2}$ for each parameter vector by running a simulation with 2,000,000 trials and initialized with a different seed, and selected that with the lowest value. We performed model comparison using AIC, which penalises models for complexity:

$$
A I C=G^{2}+2 k
$$

where $k$ is the number of free parameters. The simulated decision variables for comparison with the real LRP were obtained by subtracting the average decision variable of the incorrect option from the correct option, time-locked to stimulus onset. We did not make the simulations fall back to zero upon bound crossing, and so the signals continue to build and become less comparable to the real average LRP once it peaks and falls due to responses being made. Initially we had allowed the possible range of burst durations to be a free parameter in the BurstlE model and obtained several equally good fits in which this parameter was spread over a wide range of values, trading off with the bias magnitude. We thus decided to constrain this parameter to correspond to the real LRP as closely as possible, with the understanding that within our framework we could not be certain of its 
exact form. We fit the model four times with the burst duration range set to 30, 50, 70 and $90 \mathrm{~ms}$, and compared the time between burst onset and the low-value turnaround in the real LRP (53.7 ms) to those in the simulations. Finding the 70-ms duration range gave the closest match (52 ms), we then adjusted the duration-range parameter holding all others constant to obtain a 54-ms simulated LRP duration when the range parameter was set to $72 \mathrm{~ms}$. We adopted this value in all further fits to the BurstIE and BurstSE models.

\section{Acknowledgements}

The authors thank Louisa Spence for data collection. This study was funded by the European Union's Horizon 2020 research and innovation programme under the Marie Skłodowska-Curie grant agreement No 842143, the European Research Council Starting Grant No 63829, the European Research Council Consolidator Grant IndDecision - 865474, the Irish Research Council (GOIPD/2017/1261), and by Science Foundation Ireland Grant No 15/CDA/3591. Most of the model fitting was performed on the Lonsdale cluster which is funded through grants from Science Foundation Ireland and maintained by the Trinity Centre for High Performance Computing (Research IT, Trinity College Dublin).

\section{Competing Interests}

The authors report no competing interests.

\section{References}

Afacan-Seref, K., Steinemann, N.A., Blangero, A., Kelly, S.P., 2018. Dynamic Interplay of Value and Sensory Information in High-Speed Decision Making. Current Biology 28, 795-802.e6. https://doi.org/10.1016/j.cub.2018.01.071

Brainard, D.H., 1997. The psychophysics toolbox. Spatial vision 10, 433-436.

Brown, S.D., Heathcote, A., 2008. The simplest complete model of choice response time: Linear ballistic accumulation. Cognitive psychology 57, 153-178. https://doi.org/10.1016/j.cogpsych.2007.12.002

Churchland, A.K., Kiani, R., Shadlen, M.N., 2008. Decision-making with multiple alternatives. Nature neuroscience 11, 693-702. https://doi.org/10.1038/nn.2123

Cisek, P., Puskas, G.A., El-Murr, S., 2009. Decisions in changing conditions: the urgency-gating model. Journal of Neuroscience 29, 11560-11571. https://doi.org/10.1523/JNEUROSCI.1844-09.2009

de Lange, F.P., Rahnev, D.A., Donner, T.H., Lau, H., 2013. Prestimulus oscillatory activity over motor cortex reflects perceptual expectations. Journal of Neuroscience 33, 1400-1410. https://doi.org/10.1523/JNEUROSCI.1094-12.2013

Delorme, A., Makeig, S., 2004. EEGLAB: an open source toolbox for analysis of single-trial EEG dynamics including independent component analysis. Journal of neuroscience methods 134, 9-21. https://doi.org/10.1016/j.jneumeth.2003.10.009

Diederich, A., Busemeyer, J.R., 2006. Modeling the effects of payoff on response bias in a perceptual discrimination task: Bound-change, drift-rate-change, or two-stage-processing hypothesis. Perception \& Psychophysics 68, 194-207. https://doi.org/10.3758/BF03193669

Ditterich, J., 2006. Evidence for time-variant decision making. European Journal of Neuroscience 24, 36283641. https://doi.org/10.1111/j.1460-9568.2006.05221.x

Donner, T.H., Siegel, M., Fries, P., Engel, A.K., 2009. Buildup of choice-predictive activity in human motor cortex during perceptual decision making. Current Biology 19, 1581-1585.

https://doi.org/10.1016/j.cub.2009.07.066 
bioRxiv preprint doi: https://doi.org/10.1101/2021.03.08.434248; this version posted March 9,2021 . The copyright holder for this preprint (which was not certified by peer review) is the author/funder, who has granted bioRxiv a license to display the preprint in perpetuity. It is made available under aCC-BY 4.0 International license.

Evans, N.J., Hawkins, G.E., Boehm, U., Wagenmakers, E.-J., Brown, S.D., 2017. The computations that support simple decision-making: A comparison between the diffusion and urgency-gating models. Scientific reports 7, 1-13. https://doi.org/10.1038/s41598-017-16694-7

Feng, S., Holmes, P., Rorie, A., Newsome, W.T., 2009. Can monkeys choose optimally when faced with noisy stimuli and unequal rewards? PLoS computational biology 5, e1000284. https://doi.org/10.1371/journal.pcbi.1000284

Feuerriegel, D., Jiwa, M., Turner, W.F., Andrejević, M., Hester, R., Bode, S., 2019. Tracking dynamic adjustments to decision making and performance monitoring processes in conflict tasks. BioRxiv. https://doi.org/10.1101/2019.12.19.883447

Gluth, S., Rieskamp, J., Büchel, C., 2013. Classic EEG motor potentials track the emergence of value-based decisions. Neurolmage 79, 394-403. https://doi.org/10.1016/j.neuroimage.2013.05.005

Gold, J.I., Shadlen, M.N., 2003. The influence of behavioral context on the representation of a perceptual decision in developing oculomotor commands. Journal of Neuroscience 23, 632-651. https://doi.org/10.1523/JNEUROSCI.23-02-00632.2003

Gratton, G., Coles, M.G., Sirevaag, E.J., Eriksen, C.W., Donchin, E., 1988. Pre-and poststimulus activation of response channels: a psychophysiological analysis. Journal of Experimental Psychology: Human perception and performance 14, 331. https://doi.org/10.1037/0096-1523.14.3.331

Hanks, T., Kiani, R., Shadlen, M.N., 2014. A neural mechanism of speed-accuracy tradeoff in macaque area LIP. Elife 3, e02260. https://doi.org/10.7554/eLife.02260

Hanks, T.D., Mazurek, M.E., Kiani, R., Hopp, E., Shadlen, M.N., 2011. Elapsed decision time affects the weighting of prior probability in a perceptual decision task. Journal of Neuroscience 31, 6339-6352. https://doi.org/10.1523/JNEUROSCI.5613-10.2011

Kayser, J., Tenke, C.E., 2006. Principal components analysis of Laplacian waveforms as a generic method for identifying ERP generator patterns: I. Evaluation with auditory oddball tasks. Clinical neurophysiology 117, 348-368. https://doi.org/10.1016/j.clinph.2005.08.034

Kelly, S.P., Corbett, E.A., O'Connell, R.G., 2020. Neurocomputational mechanisms of prior-informed perceptual decision-making in humans. Nature Human Behaviour 1-15. https://doi.org/10.1038/s41562-020-00967-9

Kelly, S.P., O'Connell, R.G., 2013. Internal and external influences on the rate of sensory evidence accumulation in the human brain. The Journal of Neuroscience 33, 19434-19441. https://doi.org/10.1523/JNEUROSCI.3355-13.2013

Kennedy, J., Eberhart, R., 1995. Particle swarm optimization, in: Proceedings of the IEEE International Conference on Neural Networks. IEEE, Perth, Australia, pp. 1942-1948.

Leite, F.P., Ratcliff, R., 2011. What cognitive processes drive response biases? A diffusion model analysis. Judgment \& Decision Making 6.

Link, S.W., Heath, R.A., 1975. A sequential theory of psychological discrimination. Psychometrika 40, 77-105. Moran, R., 2015. Optimal decision making in heterogeneous and biased environments. Psychonomic bulletin \& review 22, 38-53. https://doi.org/10.3758/s13423-014-0669-3

Mulder, M.J., Wagenmakers, E.-J., Ratcliff, R., Boekel, W., Forstmann, B.U., 2012. Bias in the brain: a diffusion model analysis of prior probability and potential payoff. The Journal of Neuroscience 32, 2335-2343. https://doi.org/10.1523/JNEUROSCI.4156-11.2012

Murphy, P.R., Boonstra, E., Nieuwenhuis, S., 2016. Global gain modulation generates time-dependent urgency during perceptual choice in humans. Nature communications 7, 13526. https://doi.org/10.1038/ncomms13526

Nelder, J.A., Mead, R., 1965. A simplex method for function minimization. The computer journal 7, 308-313. https://doi.org/10.1093/comjnl/7.4.308

Noorbaloochi, S., Sharon, D., McClelland, J.L., 2015. Payoff information biases a fast guess process in perceptual decision making under deadline pressure: evidence from behavior, evoked potentials, and quantitative model comparison. Journal of Neuroscience 35, 10989-11011. https://doi.org/10.1523/JNEUROSCI.0017-15.2015 
bioRxiv preprint doi: https://doi.org/10.1101/2021.03.08.434248; this version posted March 9,2021 . The copyright holder for this preprint (which was not certified by peer review) is the author/funder, who has granted bioRxiv a license to display the preprint in perpetuity. It is made available under aCC-BY 4.0 International license.

O'Connell, R.G., Dockree, P.M., Kelly, S.P., 2012. A supramodal accumulation-to-bound signal that determines perceptual decisions in humans. Nature neuroscience 15, 1729-1735. https://doi.org/10.1038/nn.3248

O'Connell, R.G., Shadlen, M.N., Wong-Lin, K., Kelly, S.P., 2018. Bridging Neural and Computational Viewpoints on Perceptual Decision-Making. Trends in Neurosciences 41, 838-852. https://doi.org/10.1016/j.tins.2018.06.005

Ratcliff, R., 1978. A theory of memory retrieval. Psychological review 85, 59. https://doi.org/10.1037/0033295X.85.2.59

Ratcliff, R., McKoon, G., 2008. The diffusion decision model: theory and data for two-choice decision tasks. Neural computation 20, 873-922. https://doi.org/10.1162/neco.2008.12-06-420

Rinkenauer, G., Osman, A., Ulrich, R., Müller-Gethmann, H., Mattes, S., 2004. On the locus of speed-accuracy trade-off in reaction time: inferences from the lateralized readiness potential. Journal of Experimental Psychology: General 133, 261. https://doi.org/10.1037/0096-3445.133.2.261

Roitman, J.D., Shadlen, M.N., 2002. Response of neurons in the lateral intraparietal area during a combined visual discrimination reaction time task. Journal of neuroscience $22,9475-9489$. https://doi.org/10.1523/JNEUROSCI.22-21-09475.2002

Rorie, A.E., Gao, J., McClelland, J.L., Newsome, W.T., 2010. Integration of sensory and reward information during perceptual decision-making in lateral intraparietal cortex (LIP) of the macaque monkey. PloS one 5, e9308. https://doi.org/10.1371/journal.pone.0009308

Shinn, M., Ehrlich, D.B., Lee, D., Murray, J.D., Seo, H., 2020. Confluence of timing and reward biases in perceptual decision-making dynamics. Journal of Neuroscience 40, 7326-7342. https://doi.org/10.1523/JNEUROSCI.0544-20.2020

Simen, P., Contreras, D., Buck, C., Hu, P., Holmes, P., Cohen, J.D., 2009. Reward rate optimization in twoalternative decision making: empirical tests of theoretical predictions. Journal of Experimental Psychology: Human Perception and Performance 35, 1865. https://doi.org/10.1037/a0016926

Smith, P.L., Lilburn, S.D., 2020. Vision for the blind: visual psychophysics and blinded inference for decision models. Psychonomic Bulletin \& Review. https://doi.org/10.3758/s13423-020-01742-7

Smith, P.L., Ratcliff, R., 2009. An integrated theory of attention and decision making in visual signal detection. Psychological review 116, 283. https://doi.org/10.1037/a0015156

Smith, P.L., Ratcliff, R., 2004. Psychology and neurobiology of simple decisions. Trends in neurosciences 27, 161-168. https://doi.org/10.1016/j.tins.2004.01.006

Smith, P.L., Ratcliff, R., Sewell, D.K., 2014. Modeling perceptual discrimination in dynamic noise: Timechanged diffusion and release from inhibition. Journal of Mathematical Psychology 59, 95-113. https://doi.org/10.1016/j.jmp.2013.05.007

Standage, D., You, H., Wang, D., Dorris, M.C., 2011. Gain modulation by an urgency signal controls the speed-accuracy trade-off in a network model of a cortical decision circuit. Frontiers in computational neuroscience 5, 7. https://doi.org/10.3389/fncom.2011.00007

Stanford, T.R., Shankar, S., Massoglia, D.P., Costello, M.G., Salinas, E., 2010. Perceptual decision making in less than 30 milliseconds. Nature neuroscience 13, 379. https://doi.org/10.1038/nn.2485

Steinemann, N.A., O'Connell, R.G., Kelly, S.P., 2018. Decisions are expedited through multiple neural adjustments spanning the sensorimotor hierarchy. Nature communications 9, 1-13. https://doi.org/10.1038/s41467-018-06117-0

Summerfield, C., Koechlin, E., 2010. Economic Value Biases Uncertain Perceptual Choices in the Parietal and Prefrontal Cortices. Front. Hum. Neurosci. 4. https://doi.org/10.3389/fnhum.2010.00208

Thura, D., Beauregard-Racine, J., Fradet, C.-W., Cisek, P., 2012. Decision making by urgency gating: theory and experimental support. Journal of neurophysiology 108, 2912-2930. https://doi.org/10.1152/jn.01071.2011

Thura, D., Cisek, P., 2014. Deliberation and Commitment in the Premotor and Primary Motor Cortex during Dynamic Decision Making. Neuron 81, 1401-1416. https://doi.org/10.1016/j.neuron.2014.01.031

Urai, A.E., De Gee, J.W., Tsetsos, K., Donner, T.H., 2019. Choice history biases subsequent evidence accumulation. Elife 8, e46331. https://doi.org/https:/doi.org/10.7554/eLife.46331 
bioRxiv preprint doi: https://doi.org/10.1101/2021.03 08.434248. this version posted March 9,2021 . The copyright holder for this preprint (which was not certified by peer review) is the author/funder, who has granted bioRxiv a license to display the preprint in perpetuity. It is made available under aCC-BY 4.0 International license.

Usher, M., McClelland, J.L., 2001. The time course of perceptual choice: the leaky, competing accumulator model. Psychological review 108, 550. https://doi.org/10.1037/0033-295X.108.3.550

Van Vugt, M.K., Simen, P., Nystrom, L., Holmes, P., Cohen, J.D., 2014. Lateralized readiness potentials reveal properties of a neural mechanism for implementing a decision threshold. PloS one 9, e90943. https://doi.org/10.1371/journal.pone.0090943

Voss, A., Rothermund, K., Voss, J., 2004. Interpreting the parameters of the diffusion model: An empirical validation. Memory \& cognition 32, 1206-1220. https://doi.org/10.3758/BF03196893

Weindel, G., Anders, R., Alario, F.-X., Burle, B., in press. Assessing model-based inferences in decision making with single-trial response time decomposition. Journal of Experimental Psychology: General. https://hal.archives-ouvertes.fr/hal-03006342

White, C.N., Poldrack, R.A., 2014. Decomposing bias in different types of simple decisions. Journal of Experimental Psychology: Learning, Memory, and Cognition 40, 385. https://doi.org/10.1037/a0034851 


\section{Figure and table supplements}
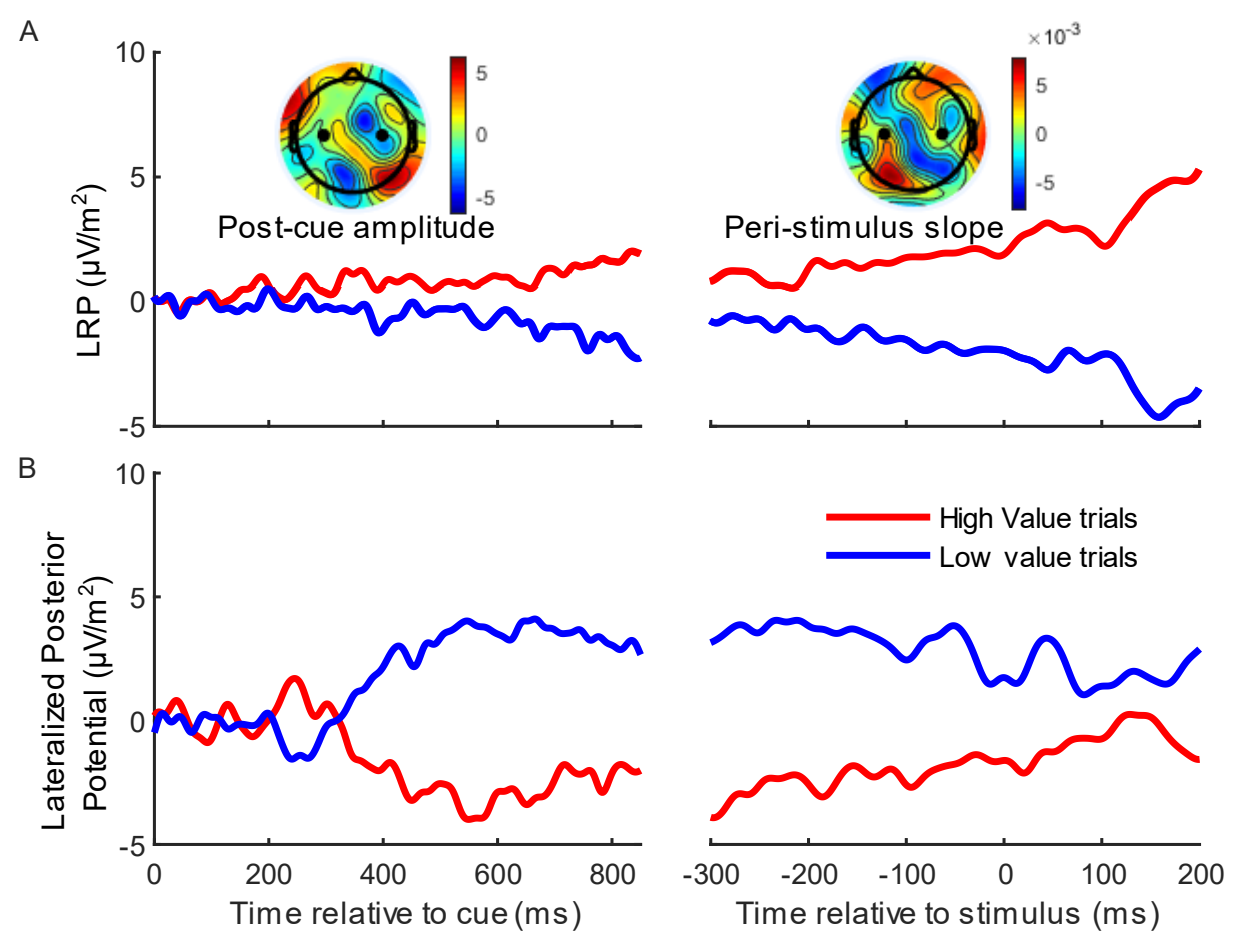

Figure 2-Figure Supplement 1. A slow-moving posterior potential interfered with measurement of the LRP between cue and motion stimulus, leading us to rely solely on Beta-band activity to examine anticipatory motor preparation. ERPs ipsilateral-contralateral to correct response, so that deflection upward corresponds to relative motor preparation in the correct direction, between cue and stimulus (left) and locked to the stimulus onset (right). A. LRP (standard sites C3/C4- see black dots in topographies), and B. Lateralized posterior potential (calculated in the exact same way as the LRP but using parietal electrodes A5 and A18 on the left; A31 and B5 on the right, Biosemi 128-channel cap). The LRP following the onset of the cue appeared to show a slowly growing bias towards the cued direction which, contrary to our findings of a tapering relative bias in Beta, persisted up to and following the stimulus onset. However, the difference topography (left inset) of left- minus right-cued trials just before stimulus onset (700-800 ms after the cue) relative to cue onset (-50-50 ms) shows that, that rather than motor preparation, the topography was dominated by a posterior potential of the opposite polarity. This slow posterior potential begins to grow at around $300 \mathrm{~ms}$ after the cue and then begins to decrease after around $600 \mathrm{~ms}$, calling for an accounting of potential overlap effects in interpreting the LRP dynamics between cue and stimulus. The relative Beta amplitude timecourse (Figure 2B) shows that relative preparation for the high value alternative begins before $400 \mathrm{~ms}$, at which time the LRP here appears quite stable. However, it is likely that the simultaneously increasing, opposing posterior potential may at that point be suppressing the expression of a motor preparation bias towards high value in the LRP. Then, as the relative Beta preparation begins to decline at around $600 \mathrm{~ms}$, the posterior potential is also beginning its decline and inducing what appears as an increasing bias to high value in the LRP. The right inset topography shows the difference in slope for left and right- cued trials from -200 to $+100 \mathrm{~ms}$ relative to the stimulus. It is clear that this slow drift towards high value visible in the LRP is primarily posterior in origin. For this reason, we did not rely on the LRP to examine the anticipatory motor preparation dynamics, but rather restricted its use to the analyses of stimulus-evoked activity, and baseline corrected the signal to stimulus onset. 
bioRxiv preprint doi: https://doi.org/10.1101/2021.03.08.434248: this version posted March 9.2021 . The copvriaht holder for this preprint (which was not certified by peer review) is the author/funder, who has granted bioRxiv a license to display the preprint in perpetuity. It is made available under aCC-BY 4.0 International license.

Table 2- Table Supplement 1. Goodness of fit metrics for main models and some with selected additional parameters.

\begin{tabular}{|l|l|l|l|l|l|}
\hline Model & Stimulus-evoked bias & Evidence & $\mathrm{k}$ & $\mathrm{G}^{2}$ & $\mathrm{AIC}$ \\
\hline BurstIE & Burst & Increasing & 14 & 39 & 67 \\
SustlE & Sustained & Increasing & 14 & 51 & 79 \\
BurstSE & Burst & Stationary & 13 & 62 & 88 \\
SustSE & Sustained & Stationary & 13 & 87 & 113 \\
BurstIE + drift boost & Burst & Increasing & 15 & 39 & 69 \\
BurstIE $+S z$ & Burst & Increasing & 15 & 38 & 68 \\
SustlE $+S z$ & Sustained & Increasing & 15 & 52 & 82 \\
BurstSE $+S z$ & Burst & Stationary & 14 & 61 & 89 \\
SustSE $+S z$ & Sustained & Stationary & 14 & 86 & 114 \\
BurstSE $+S T_{e v}$ & Burst & Stationary & 14 & 58 & 86 \\
SustSE $+s T_{e v}$ & Sustained & Stationary & 14 & 86 & 114 \\
\hline
\end{tabular}

In addition to the 4 main models described in our Results (recapitulated in the first 4 rows of this table), we fit several additional models to examine the effects of some differences in implementation with respect to a recent neurally-informed (NI) model of a broadly similar nature, described in Kelly et al., (2020). First, a central finding from that study, which involved an extreme speed-pressure manipulation, was that the drift-rate parameter of the NI model increased under speed pressure for the same stimulus coherence. Thus, the: "BurstIE + drift boost" model allowed an additional drift boost parameter in the high-coherence blocked condition, relative to high-coherence interleaved. This resulted in an identical $G^{2}$, suggesting that in this case the much more subtle speed pressure manipulation between the conditions was not sufficient to replicate the effect. Second, the NI model of Kelly et al., (2020) had a uniformly distributed starting-level variability with a range parameter, sz, applied independently to the constrained mean starting levels of the decision variables. This parameter did not improve our fits to any of the 4 models (listed in rows 6-9). Third, it was possible that the effect of the gradual integration of motion evidence could be captured in the SE models by allowing for variability in the evidence onset time, $T_{\text {ev }}$. Whereas Kelly et al., (2020) incorporated variability in accumulation onset relative to a fixed evidence onset time, it was more convenient here to incorporate a qualitatively similar feature by varying evidence onset, since accumulation onset was anchored to the onset of the LRP bolus response. We found that adding such variability, uniformly distributed with range $s T_{e v}$, very slightly improved performance of the BurstSE model and did not help the SustSE model. Neither were improved to an extent where they could compete with the best-fitting BurstIE model. 
bioRxiv preprint doi: https://doi.org/10.1101/2021.03 08.434248; this version posted March 9, 2021. The copyright holder for this preprint (which was not certified by peer review) is the author/funder, who has granted bioRxiv a license to display the preprint in perpetuity. It is made available under aCC-BY 4.0 International license.

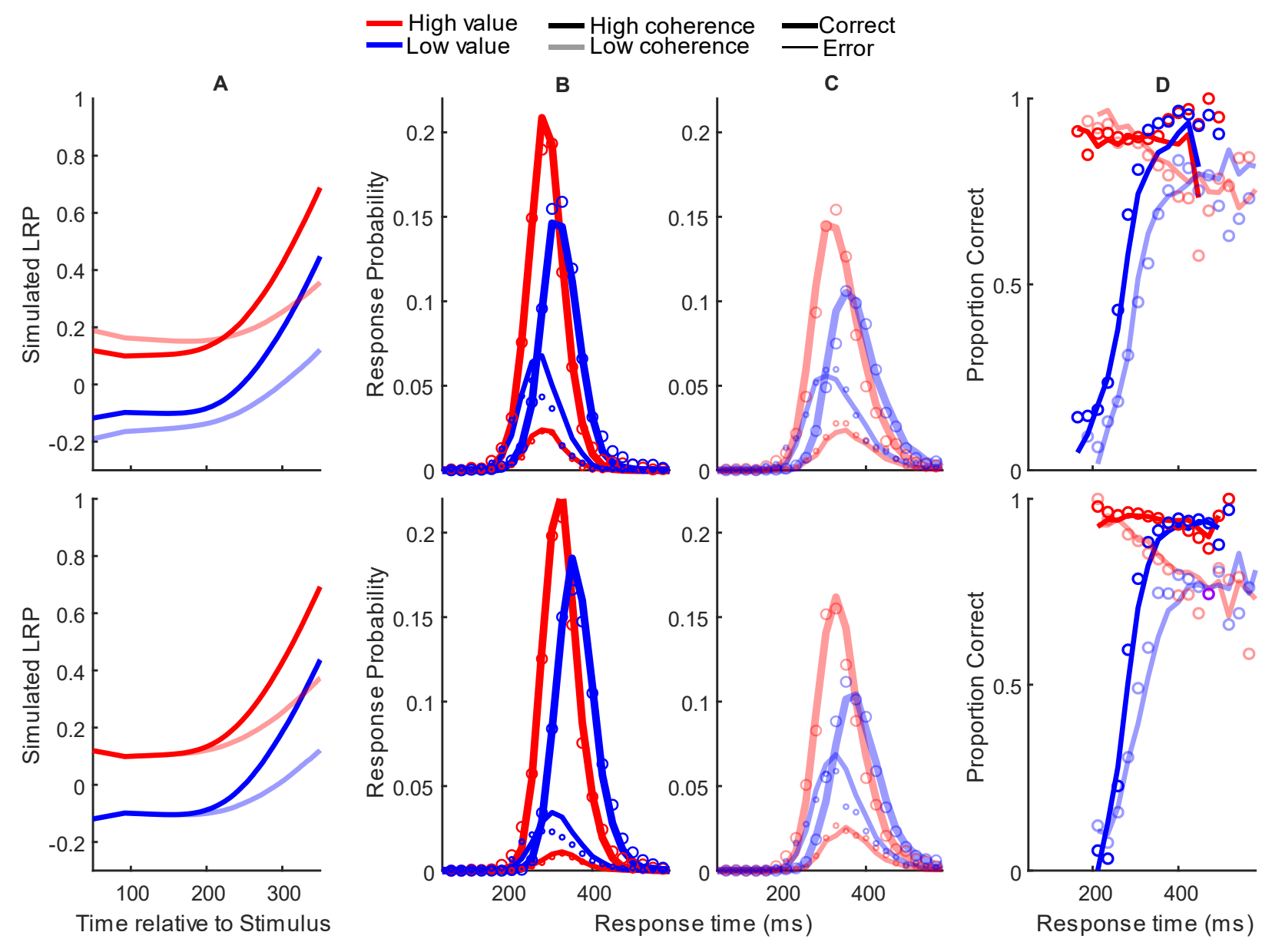

Figure 4-Figure Supplement 1. SustlE model-simulated waveforms and behavior for blocked session (top row) and interleaved session (bottom row). A Mean difference between simulated DVs; B-C Real (circles) and model-simulated (solid lines) RT distributions. D Real and model-simulated CAFs. 
bioRxiv preprint doi: https://doi.org/10.1101/2021.03 08.434248; this version posted March 9, 2021. The copyright holder for this preprint (which was not certified by peer review) is the author/funder, who has granted bioRxiv a license to display the preprint in perpetuity. It is made available under aCC-BY 4.0 International license.

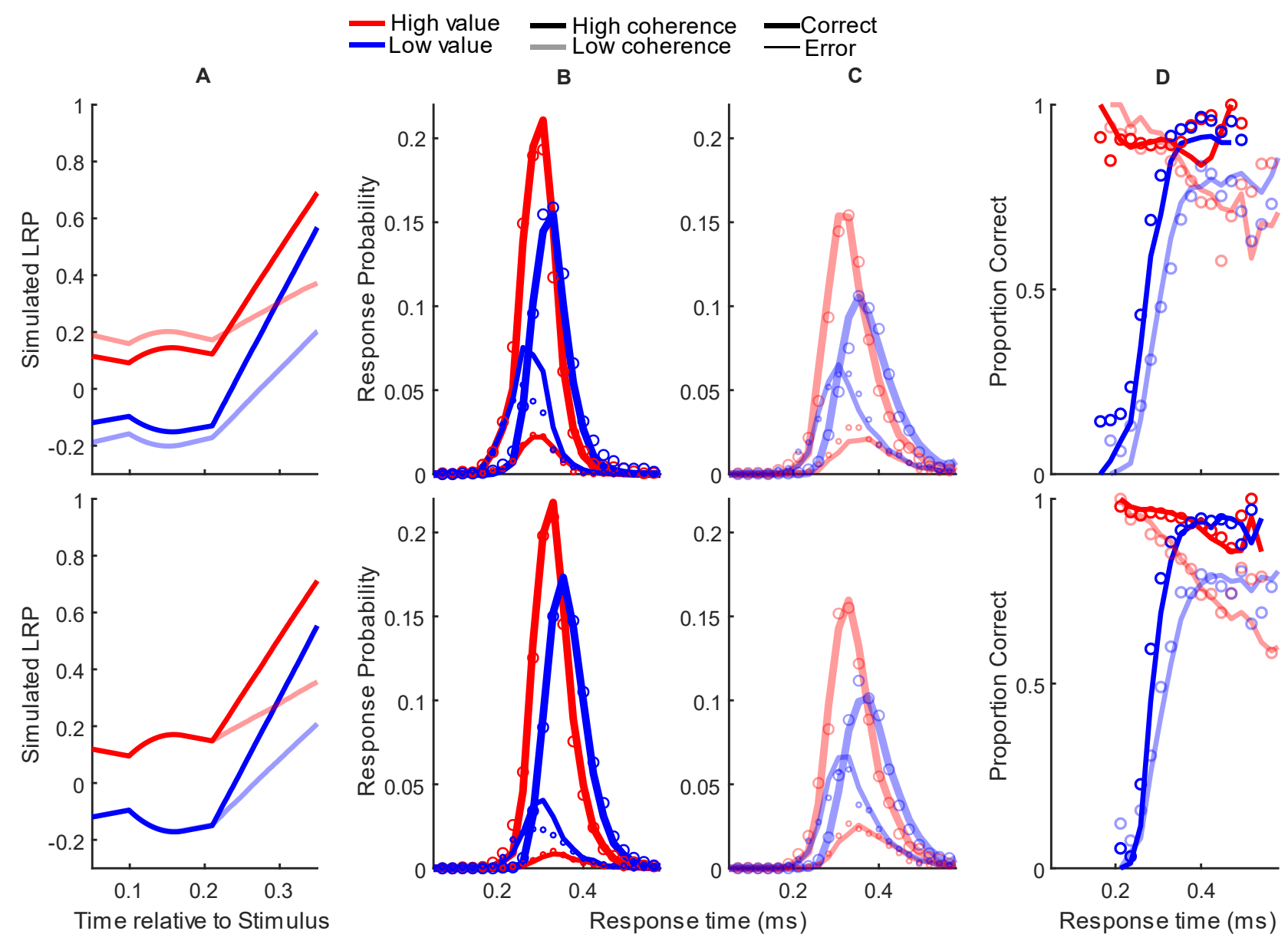

Figure 4-Figure Supplement 2. BurstSE model-simulated waveforms and behavior for blocked session (top row) and interleaved session (bottom row). A Mean difference between simulated DVs; B-C Real (circles) and model-simulated (solid lines) RT distributions. D Real and model-simulated CAFs. 
bioRxiv preprint doi: https://doi.org/10.1101/2021.03.08.434248. this version posted March 9.2021 . The copyright holder for this preprint (which was not certified by peer review) is the author/funder, who has granted bioRxiv a license to display the preprint in perpetuity. It is made available under aCC-BY 4.0 International license.

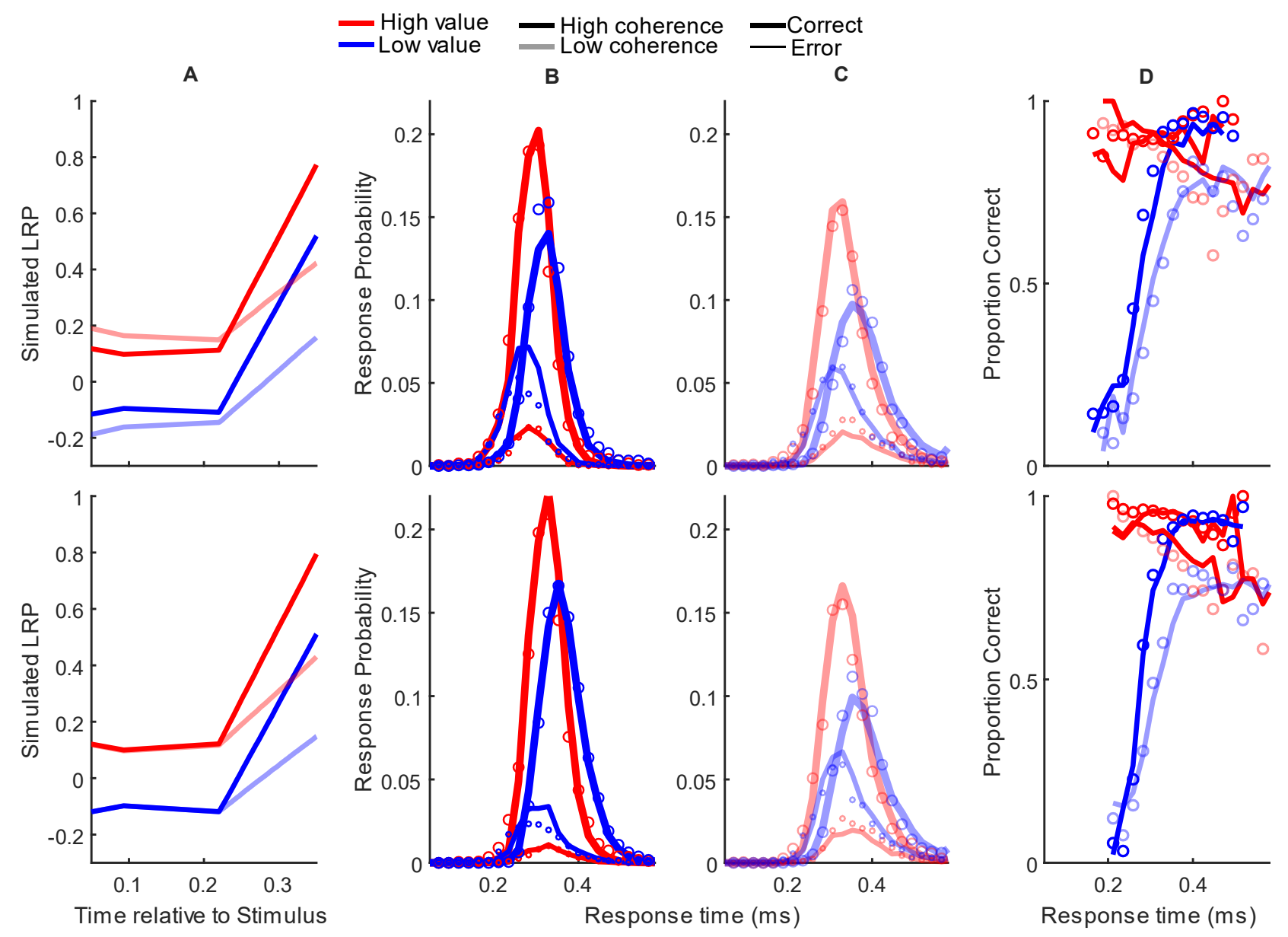

Figure 4-Figure Supplement 3. SustSE model-simulated waveforms and behavior for blocked session (top row) and interleaved session (bottom row). A Mean difference between simulated DVs; B-C Real (circles) and model-simulated (solid lines) RT distributions. D Real and model-simulated CAFs.

Figure 5-Supplementary Table 1. Beta start-points and slopes for individually-selected electrodes and $\mathrm{C} 3 / \mathrm{C} 4$.

\begin{tabular}{|c|c|c|c|c|c|c|}
\hline \multirow[t]{2}{*}{ Parameter } & \multicolumn{3}{|c|}{ Individually selected } & \multicolumn{3}{|c|}{$\mathrm{C} 3 / \mathrm{C} 4$} \\
\hline & $\begin{array}{c}\text { High } \\
\text { Coherence }\end{array}$ & $\begin{array}{c}\text { Low } \\
\text { Coherence }\end{array}$ & Interleaved & $\begin{array}{c}\text { High } \\
\text { Coherence }\end{array}$ & $\begin{array}{c}\text { Low } \\
\text { Coherence }\end{array}$ & Interleaved \\
\hline$Z_{c}$ & .32 & .3 & 2 & .32 & .36 & .2 \\
\hline$Z_{i}$ & .12 & .002 & 0 & .11 & .06 & 0 \\
\hline $\overrightarrow{U_{c}}$ & 1.36 & 1.09 & 1.3 & 1.25 & 0.96 & 1.17 \\
\hline$U_{i}$ & 1.83 & 1.7 & 1.79 & 1.66 & 1.61 & 1.62 \\
\hline
\end{tabular}

